MOL. 19980615.0221

\title{
Modifications and Additions to Selected TOUGH2 Modules
}

\author{
Y. S. Wu and A. K. Mishra \\ Earth Sciences Division, \\ E. O. Lawrence Berkeley National LaboratoryBerkeley, \\ California, U. S. A.
}

\section{Introduction}

The purpose of this report is to provide all software baseline documents necessary for the software qualification of the revised versions of the selected TOUGH2 modules, which include single-phase gas (EOS1G), effective continuum method (EOS3/ECM), saturated/ unsaturated flow (EOS9), and radionuclide transport (T2R3D) modules of the TOUGH 2 code. TOUGH 2 is a numerical simulation code for multi-dimensional, coupled fluid and heat flow of multiphase, multicomponent fluid mixtures in porous and fractured media. This report augments the document Software Qualification of Selected TOUGH2 modules (Wu et al., 1996).

Wu and others (1996) have documented the software qualification of the original versions of the single-phase gas (EOS1G), effective continuum method (EOS3/ECM), saturated/unsaturated flow (EOS9), and radionuclide transport (T2R3D) modules of TOUGH2. Subsequent to the software qualification reported in the above document, a number of additions and modifications have been carried out to these modules as requested by the Yucca Mountain project. In accordance with Yucca Mountain Project (YMP)/ Lawrence Berkeley National Laboratory (LBNL) Quality Implementing Procedure YMPLBNL-QIP-SI.0, Software Qualification, all the changes are explicitly listed out along with the need/rationale for the modifications/additions.

This report contains the following sections: 1) Requirement specifications and code development and 2) Software validation test plan and results. These sections comprise sequential parts of Software Lifecycle, and should be used in conjunction with the TOUGH User's Guide (Pruess, 1987), TOUGH2 documentation (Pruess, 1991), TOUGH2 Software Qualification (Pruess et al., 1996), and Software Qualification of Selected TOUGH2 modules (Wu et al., 1996).

The version of TOUGH2 used with the software being qualified herein is the December 1997 Standard Version 1.3, as qualified in Wu et al. (1996) and housed at the Department of Energy's Energy Science and Technology Software Center (ESTSC) in Oak Ridge, Tennessee.

\section{TOUGH 2 and MULKOM}

TOUGH2, a numerical simulator for non-isothermal flows of multicomponent, multi-phase fluids in porous and fractured media (Pruess, 1987,1991; Pruess et al. 1996), belongs to the MULKOM family of codes (Pruess, 1983, 1988) and is a more general version of the TOUGH simulator (Pruess, 1987). TOUGH2 is essentially a subset of 
MULKOM, consisting of a selection of the better tested and documented MULKOM program modules. The MULKOM family of multi-phase, multi-component codes were developed at Lawrence Berkeley Laboratory primarily for geothermal reservoir applications (Pruess, 1983).

\section{Prior Examples of Requirement Verification}

TOUGH 2 has been verified and benchmarked by many fluid and heat flow problems that involved one, two, and three-dimensional flows, with varying degrees of non-linearity and coupling between heat and fluid flows, and different boundary conditions. These results substantiate the accuracy of the process description as well as the mathematical and numerical approaches used. See section 3 (Wu et al., 1996) for the design and description of the problems and section 4 (Wu et al., 1996) for the validation tests for the modules mentioned above.

In terms of the integral formulation, the conservation equations of mass and thermal energy, solved by the standard TOUGH2 code, are described (Pruess, 1991) by

$$
\frac{d}{d t} \int_{V_{\text {a }}} M^{(x)} d V=\int_{\Gamma_{\text {a }}} \mathrm{F}^{(\kappa)} \cdot \mathbf{n} d \Gamma+\int_{V_{\text {a }}} q^{(\boldsymbol{x})} d V
$$

The integration here is over an arbitrary subdomain $V_{n}$ of the flow system under study, which is bounded by the closed surface $\Gamma_{\mathbf{z}}$. The quantity $M$ appearing in the accumulation term denotes mass or energy per unit volume, with $k=1$ (air) and $k=2$ (water), labeling the mass components, and $\kappa=3$ for "heat" component. $F$ is a general "flow" term including multiphase Darcy's flow, mass advection/diffusion transport and heat convection/conduction transfer, $n$ is an unit vector normal to the surface $\Gamma$ and $q$ is a sink/source term.

Based on the "integral finite difference" method (Edwards, 1972; Narasimhan and Witherspoon, 1976) the continuum equations are discretized in space using appropriate volume averages and surface integrals approximated as a discrete sum of averages over suraface segments $A_{\text {mn }}$ [see Appenix B of Pruess(1991) for details]. Time is discretized as a first order backward difference which results in the following set of coupled non-linear, algebraic equations

$$
R_{n}^{x, k+1}=M_{n}^{x, k+1}-M_{n}^{x, k}-\frac{\Delta r}{V_{n}}\left[\sum_{m} A_{n m} F_{n m}^{*, k+1}+V_{n} q_{n}^{x, k+1}\right]=0
$$

The component flux:

$$
F_{R m}^{*}=\sum_{\beta} X_{\beta}^{\mathrm{r}} F_{\beta, m}
$$

where $X_{\beta}$ is mass fraction of component $\kappa$ in phase $\beta$. Individual phase mass fluxes, $F_{\beta, m m}$, are given by a multi-phase version of Darcy's law:

$$
F_{\beta, n m}=-k_{n m}\left[\frac{k_{n \beta} \rho_{\beta}}{\mu_{\beta}}\right]_{n m}\left[\frac{P_{\beta, n}-P_{\beta, m}}{D_{n m}}-\rho_{\beta, n m} g_{n m m}\right]
$$


In Equation (4), $k_{\mathrm{mm}}$ is the absolute permeability, $k_{t b}$ is relative permeability of phase $b, m_{b}$ is viscosity of phase $b$, and $P_{b}$ is the pressure in phase $b$. $g_{n m}$ denotes a component of the vector of gravitational acceleration.

The entire geometric information of the space discretization in Equations (2) and (4) is provided through the grid block volumes $V_{n}$, interface area $A_{m n}$, nodal distances $D_{m n}$ and components $g_{\operatorname{man}}$ of gravitational acceleration along nodal lines. The subscript (nm) denotes a suitable averaging at the interface between grid blocks $\mathbf{n}$ and $\mathbf{m}$ using the various weighting schemes.

\section{Requirement Specifications and code development} following:

Changes made to address specific issues in each of the modules are listed as the

\subsection{Interface area reduction scheme}

For studying flow and transport in unsaturated fractured media, an important aspect is the evaluation of interaction between matrix blocks and the surrounding fractures. In the dual-permeability model, the fractured blocks interact with the matrix blocks according to the interface area between the two connecting blocks and their respective state variables. In the previous qualified version (Pruess et al., 1996), the complete fracture-matrix interface area was available by the setting isotropic parameter, ISOT $=1$, for each fracture-matrix connection. However, there is evidence that fracture-matrix interaction in the unsaturated zone at Yucca Mountain is limited due to fingering flow in fractures (Glass et al., 1996) and mineral coatings on the fracture surfaces, and in fact there may be only part of fracturematrix interface areas that contributes fracture-matrix inter flow. Details of the conceptual models to reduce the fracture-matrix interface area have been proposed by Thoma et al. (1992), Altman et al. (1996), Ho (1997), and Bodvarsson et al. (1997).

In TOUGH2 the input data specified in CONNE introduces information for the connection between elements (Pruess, 1987). The format is as given below

Card CONNE.1

Format $(\mathrm{A} 3,12, \mathrm{A3}, \mathrm{I2}, 4 \mathrm{IS}, 4 \mathrm{E} 10.4)$

L1, NE1, EL2, NE2, NSEQ, NAD1,NAD2, ISOT, D1, D2,AREAX, BETAX

Specifically in CONNE.1, the parameter ISOT is set equal to 1,2 or 3 which allows assignments of different anisotropic permeabilities for the materials in elements (EL1, NE1) and (EL2, NE2) making up the connection. AREAX is the interface area $\left(m^{2}\right)$.

A number of reduction approaches for fracture/matrix interface areas have been implemented for use in the dual-permeability flow simulations of the UZ model. Different cases are treated in all the revised modules by setting ISOT to a proper negative value which triggers different treatment for the reduction of the fracture-matrix interface area. These are discussed in detail in the section related to validation test plan and results.

\subsection{Modified weighting scheme for vitric/zeolitic interface}

The TOUGH2 code is presently used for modeling fluid and heat flow and chemical transport at the Yucca Mountain site. A major task in building the numerical model is an accurate representation of the complex geological layering and structure resulting from 
numerous periods of volcanism and tectonism since the Miocene. In the vertical direction, heterogeneities primarily result from the deposition of ash flow and air fall tuffs found beneath Yucca Mountain. One major complexity is the post-depositional activity related to hydrothermal alteration. This is of special importance in the hydrologically significant vitric and zeolitic portions of the Calico Hills and Prow Pass formations, because permeabilities vary by several orders of magnitude when crossing the vitric/zeolitic interfaces in these units (Hinds et al., 1997; Bandarruga et al., 1997).

For the vertical vitric/zeolitic matrix-matrix interface, a modified downstream weighting scheme has been proposed and implemented into the TOUGH2 code. In this scheme, vertical downward matrix to matrix flow is evaluated using the mobility of the underlying, low-permeable zeolitic blocks in order to avoid over-estimates of flow into the zeolitic matrix blocks. It should be mentioned that in petroleum literature, upstream weighting is traditionally used for relative permeabilities and harmonic weighting is used for absolute permeabilities in handling multi-phase flow in porous media. This conventional technique works reasonably well for cases of multiphase flow as long as contrasts in flow properties of adjacent formation layers are not very large, such as in single porosity media. For simulating multiphase flow in fractured/porous media, Tsang and Pruess (1990) recognized that this traditional weighting scheme gives artificial flow resistance and can lead to physically incorrect solutions for highly heterogeneous composite formations with alternate layers of non-welded and welded tuffs, such as at Yucca Mountain. Therefore, except for the vitric/zeolitic matrix-matrix connections, full upstream weighting scheme is recommended to use for both relative and absolute permeabilities in order to obtain physically plausible solutions.

\subsection{Post-processing for mass flux and flow velocity}

A new subroutine for the calculation of the velocity and mass flux at each node is developed. This subroutine (vel_c) takes into account the irregular features of the grid and calculates the pore velocity and mass flux vectors using the state variables in the neighbouring elements at user's specified time steps. The objective of this subroutine is to speed up the post-processing in analyzing the TOUGH2 output, because neither pore velocity nor mass flux in the global coordinates is given in the standard TOUGH2 output.

The procedure for converting the local fluxes along connections in the local coordinates to a mass flux, $F_{\mathrm{z}}$ in the global coordinates $(x, y, z)$ at the block center for block $n$ of the grid is through the "projected area weighting method" (Wu et al., 1996). In this weighting scheme, the flux component, $F_{\mathrm{a}}$ of the vector $F_{\mathrm{z}}$ is computed as the vectorial summation of the components of all local connection vectors in the same direction, weighted by the projected area in that direction,

$$
F_{n, i}=\frac{\sum_{m}\left(A_{x m}\left|n_{1}\right|\right)\left(F_{n m} n_{i}\right)}{\sum_{m}\left(A_{n m}\left|n_{i}\right|\right)} \quad(i=x, y, z)
$$

where $\mathbf{m}$ is the total number of connections between element $\mathbf{n}$ and all its neighbouring elements $m$ and $F_{n m}$ is the flux along connection $n m$ in the local coordinate system. $n_{i}$ with $i=x, y$ and $z$ is the component in the $x-, y-$, and $z$-direction, respectively, of the unit vector $\mathrm{n}$ vector along the connection line $\mathrm{nm}$ between the two blocks $\mathrm{n}$ and $\mathrm{m}$. In Equation (5), the term $\left[A_{\operatorname{mom}} \mid n_{1}\right]$ is the projected area of the interface $A_{\operatorname{mm}}$ on the direction $i$ of the global coordinate system, and $\left(F_{\mathrm{mm}} n_{j}\right)$ gives the flux component in the direction $i$ of the global coordinate system contributed by the local flux $F_{m}$ between blocks $n$ and $m$. 
Similarly, a component, $v_{\mathrm{a}, \mathrm{y}}$ ( $\mathrm{i}=\mathrm{x}, \mathrm{y}$ and $\mathrm{z}$ ) of the pore velocity vector $\left(\mathrm{v}_{\mathrm{a}}\right)$ at a center of element block $n$ is calculated by,

$$
v_{n, l}=\frac{\sum_{m}\left(\left|n_{i}\right|\right)\left(v_{m n} n_{i}\right)}{\sum_{m}\left(\left|n_{i}\right|\right)} \quad(i=x, y, z)
$$

Here a velocity component is weighted only by the interface area direction cosines.

\subsection{Output files for visualization}

The input data specified in block PARAM sets up the various computation parameters (Pruess, 1987). In particular in PARAM.1 a set of input parameters denoted by MOP(I), I=1, 24 are used. MOP(23) and MOP(24) are the two data fields that need to be specified to obtain the output files needed for visualization. The generation of the output is invoked by setting $\operatorname{MOP}(23)=1$ or 2 . $\operatorname{MOP}(23)=0$ does not lead to the post processing for flow velocity and flux calculations. Setting $M O P(23)=1$ leads to the various primary variables (pressure, temperature, liquid saturation, fracture saturation, and matrix saturation, capillary pressures and etc.) to be written to a file tough2.tec for non-dual permeability grids. For the dual permeability grids, tough2.tec is the output file for the matrix along with an additional file tough f.tec for the fractures. $\operatorname{MOP}(23)=2$ writes out the additional information about fluid velocities and mass fluxes besides the various primary variables listed above. $\mathrm{MOP}(24)=0$ is a flag for non-dual permeability fields and $\operatorname{MOP}(24)=1$ is for dual permeability simulations.

The output is written in a format suitable for prompt and easy visualization with standard commercial software used at LBNL. The post processing subroutine calculates the velocities and the mass fluxes in each of the three directions $(x, y, z)$ for both the fracture and the matrix continuums. The nomenclature used in the output files for velocity and mass fluxes is as given below:
$\mathrm{P}$ - Pressure, $\mathrm{Pa}$
SL - Liquid saturation
T - Temperature, ${ }^{\circ} \mathrm{C}$
Pcap-Capillary pressure, $\mathrm{Pa}$
VLX - Liquid velocity in $\mathrm{x}$ direction, $\mathrm{m} / \mathrm{s}$
VLy - Liquid velocity in y direction, $\mathrm{m} / \mathrm{s}$
$\mathrm{VLz}$ - Liquid velocity in $\mathrm{z}$ direction, $\mathrm{m} / \mathrm{s}$
VFX - Liquid velocity in the fractures in $\mathrm{x}$ direction, $\mathrm{m} / \mathrm{s}$
VFy - Liquid velocity in the fractures in $y$ direction, $\mathrm{m} / \mathrm{s}$
VFz - Liquid velocity in the fractures in $\mathrm{z}$ direction, $\mathrm{m} / \mathrm{s}$
$\mathrm{VMx}$ - Liquid velocity in the matrix in $\mathrm{x}$ direction, $\mathrm{m} / \mathrm{s}$
$\mathrm{VMy}$ - Liquid velocity in the matrix in y direction, $\mathrm{m} / \mathrm{s}$
$\mathrm{VMz}$ - Liquid velocity in the matrix in z direction, $\mathrm{m} / \mathrm{s}$
FFx - Mass flux in the fractures in $\mathrm{x}$ direction, $\mathrm{kg} / \mathrm{s} / \mathrm{m}^{2}$
FFy - Mass flux in the fractures in y direction, $\mathrm{kg} / \mathrm{s} / \mathrm{m}^{2}$
FFz - Mass flux in the fractures in $\mathrm{z}$ direction, $\mathrm{kg} / \mathrm{s} / \mathrm{m}^{2}$
FMx - Mass flux in the matrix in $\mathrm{x}$ direction, $\mathrm{kg} / \mathrm{s} / \mathrm{m}^{2}$
FMy - Mass flux in the matrix in y direction, $\mathrm{kg} / \mathrm{s} / \mathrm{m}^{2}$
FMz - Mass flux in the matrix in $\mathrm{z}$ direction, $\mathrm{kg} / \mathrm{s}^{\mathrm{m}} \mathrm{m}^{2}$
Ff-m - Mass flow rate between fractures and matrix, $\mathrm{kg} / \mathrm{s}$ 


\subsection{Capillary pressure modification at residual water saturation}

The standard TOUGH2 code allows for a selection of seven different capillary pressure versus water saturation functions (Pruess, 1987). In the case that van Genuchten's function (van Genuchten, 1980) is used, the capillary pressure increases very rapidly when liquid saturation is near residual water saturation. The theoretical limit at residual water saturation is infinity. Numerically the infinite pressure condition was avoided by imposing a finite, large value (such as $1.00 \mathrm{E}+11 \mathrm{~Pa}$ and higher) at the residual water saturation.

It has been observed, especially in modelling thermo-hydrological conditions in the unsaturated zone at Yucca Mountain, that heated rocks due to the thermal loading imposed on the system often lead to saturation conditions very near or even lower than residual saturations due to dry out of the matrix. However simulations of such drastic conditions were numerically very inefficient and unstable. It was very difficult to obtain numerical solutions due to numerical instability. This was of crucial concern in terms of computational times needed by the large number of simulations runs required for Total System Viability Assessment (TSVA) calculations for Yucca Mountain Project.

From a physical perspective, neither of the two conditions of infinite capillary pressure or a large cutoff value (discontinuity in derivative of the function) is correct. It was therefore decided to implement a linear interpolation scheme for capillary pressure at saturations near residual conditions. For a specified small value ( $e=1.0 e-5$ is the default), if the water saturation $\left(S_{w}\right)$ decreases to less than $S_{w+}+e$, the linear interpolation scheme is used to calculate the capillary pressure based on the slope of the straight line which is drawn tangent to the capillary pressure curve at a saturation of $S_{\text {wir }}+e$ (Figure 1). This option is invoked only if $I C P(1)=10$, where ICP is the integer parameter to choose the type of capillary function specified in the input parameter set in ROCKS.1.3 of TOUGH2. 


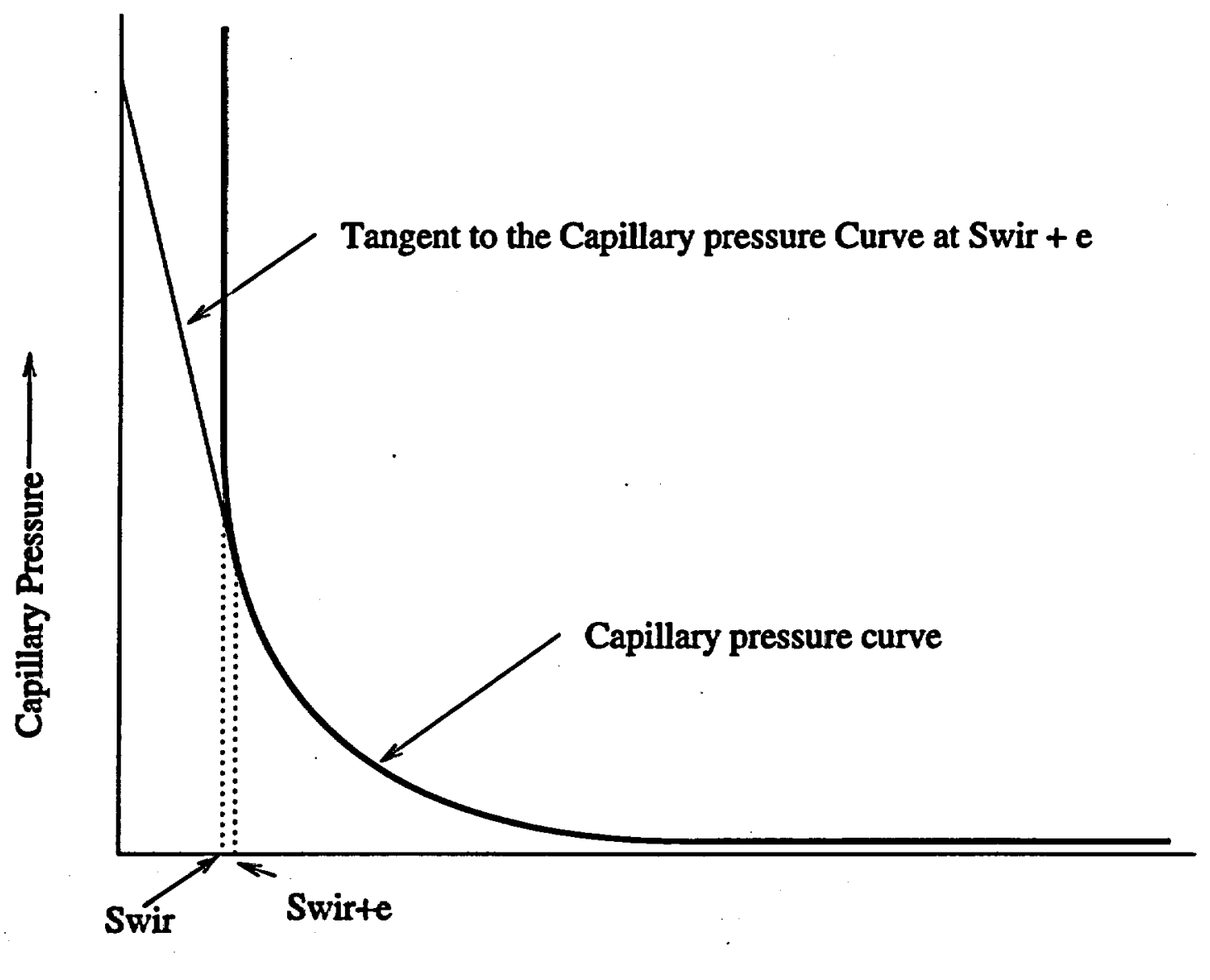

Water Saturation $\longrightarrow$

Figure 1. Schematic representation of the linear extrapolation scheme for capillary pressure at residual water saturation.

\subsection{Data input for spatially varying rock properties}

The rock properties for the various layers identified in the numerical model are input through the ROCKS.1 block in the input file. The implicit assumption using this format is that the various rock properties like permeability, porosity, grain density, thermal conductivity and rock grain specific heat are constant for a given rock type.

It is, however, common knowledge that most of these rock properties are heterogeneous. The spatial variability of a parameter is usually modeled using spatial random functions. Even though it is possible to input different material properties for each grid block using the qualified version of the TOUGH2 modules, computer storage and computational intensity become enormous when dealing with 3-D site-scale field problems. Therefore, special data input format for spatially varying rock properties and special treatment in the code are introduced here to improve the requirement of storage and computational intensity for large, spatially varying parameter cases. Various geostatistical techniques are available to generate the values of he parameter at each node from a set of measured values at various locations. The spatially varying case is used by the TOUGH2 
code only when the keyword SVPAR is present in the input file. The method adopted in TOUGH2 is to set a flag isvpara $=1$ and read an input file svparam.dat which reads the porosity, rock grain density and thermal conductivity for each element of the model. The default condition is isvpara $=0$ in which case the rock properties from the input data set as specified in ROCKS is read in (Pruess, 1987).

\subsection{Addition of a relative permeability function in EOS3/EOS9/T2R3D}

The Brooks-Corey relative permeability function (Brooks and Corey, 1964) was added to the suite of other functions that are presently available in TOUGH2. This function has not been used in the UZ model to this date. In this formulation

$$
\begin{aligned}
& k_{r t}=\left(S_{l}^{*}\right)^{\frac{2+3 \lambda}{\lambda}} \\
& k_{r g}=1-k_{r l}
\end{aligned}
$$

or $k_{n}=\left(1-S_{l}^{*}\right)^{2}\left[1-\left(S_{l}^{*}\right)^{\frac{2+\lambda}{\lambda}}\right]$

where $S_{l}^{*}=\frac{S_{l}-S_{l r}}{1-S_{l r}-S_{g g}}$

and $\lambda=\frac{m}{1-m}$

$\lambda$ is a soil characteristic parameter and is related to $\mathrm{m}$, the vanGenuchten parameter (van Genuchten, 1980), $S_{k}$ is the residual liquid saturation and $S_{k \pi}$ is the residual gas saturation.

\subsection{Addition of a relative permeability function in EOS1G}

The qualified version of the TOUGH 2 model is based on an explicit form of relative permeability to the liquid phase $k_{r t}$ with the relative permeability to gas phase in the matrix, assumed to be $k_{1}=1-k_{r i}$. However, the parameter of interest for the propagation of pneumatic signal through the unsaturated rocks is diffusivity, which is the ratio of the permeability to the air-filled porosity of a model layer. The primary pathway for gas is assumed to be through the fractures in the densely welded rock strata. The matrix porosity adjacent to fractures contributes little to gas flow but causes signal attenuation due to storage in the relatively large pore spaces. For the dual-permeability model with one matrix gridblock per layer, the $\left(1-k_{\mathrm{fl}}\right)$ formulation requires the estimated fracture permeability in the model to increase by several orders of magnitude in order to propagate the pneumatic signal down to the lower model layers (Bandurraga and Bodvarsson, 1997). The increases are not consistent with the air-k test results of LeCain (1997). Therefore, the Brooks-Corey type gas relative permeability model (Luckner et al., 1989) was instituted for the matrix to reduce $\mathrm{k}_{\mathrm{Tg}}$. The new functional form of the relative permeability function gives rise to a larger interference of the gas phase. The new formulation provided a better match to the pneumatic test data.

The form of the equation is given by 


$$
\begin{aligned}
& S=\frac{S_{l}-S_{l r}}{S_{\max }-S_{l r}} \\
& k_{r g}=(1-S)^{2}\left[1-S^{\frac{2+\lambda}{\lambda}}\right] \\
& \lambda=\frac{m}{1-m}
\end{aligned}
$$

where $S_{1}$ is the liquid saturation, $S_{r}$ and $S_{\max }$ are the minimum and maximum liquid saturation (given as input in the ROCKS block as RP(2,mat) and RP(3,mat)) and $m$ is the van Genuchten fitting parameter specified by RP(1,mat).

\section{Validation Tests}

The validation tests for the revised modules consists of developing a sample problem set which addresses a specific issue (different interface area reduction scheme, for example) and using the qualified code and the revised code to check the output in each case for output variables. Very similar results (differences less than $1 \%$ ) between the two versions of the codes would then lead to the conclusion that the revised code performs acceptably for qualification.

\subsection{Sample problem 1:}

Effective Continuum Method Module (ECM) using the EOS3 module

The sample problem considers one-dimensional (1-D) vertical flow in the unsaturated zone of Yucca Mountain and a single vertical column is extracted directly from the 3-D site scale model (Bodvarsson et al., 1997). The boundary condition specified is Dirichlet-type conditions. The bottom boundary is treated as being at constant gas pressure, liquid saturation, and temperature by specifying a large volume. A liquid water source is introduced to the second element from the top to provide constant water infiltration. See Figure $\mathbf{2}$ for the input file and Figure 3 for the output file. The results of simulations are presented in Table 1-4. Tables 1 and 2 compare the pressures in each element between the two versions of the code and show that the output is identical in both the cases. A similar conclusion is reached when the liquid fluxes are compared (Tables 3,4 ). 


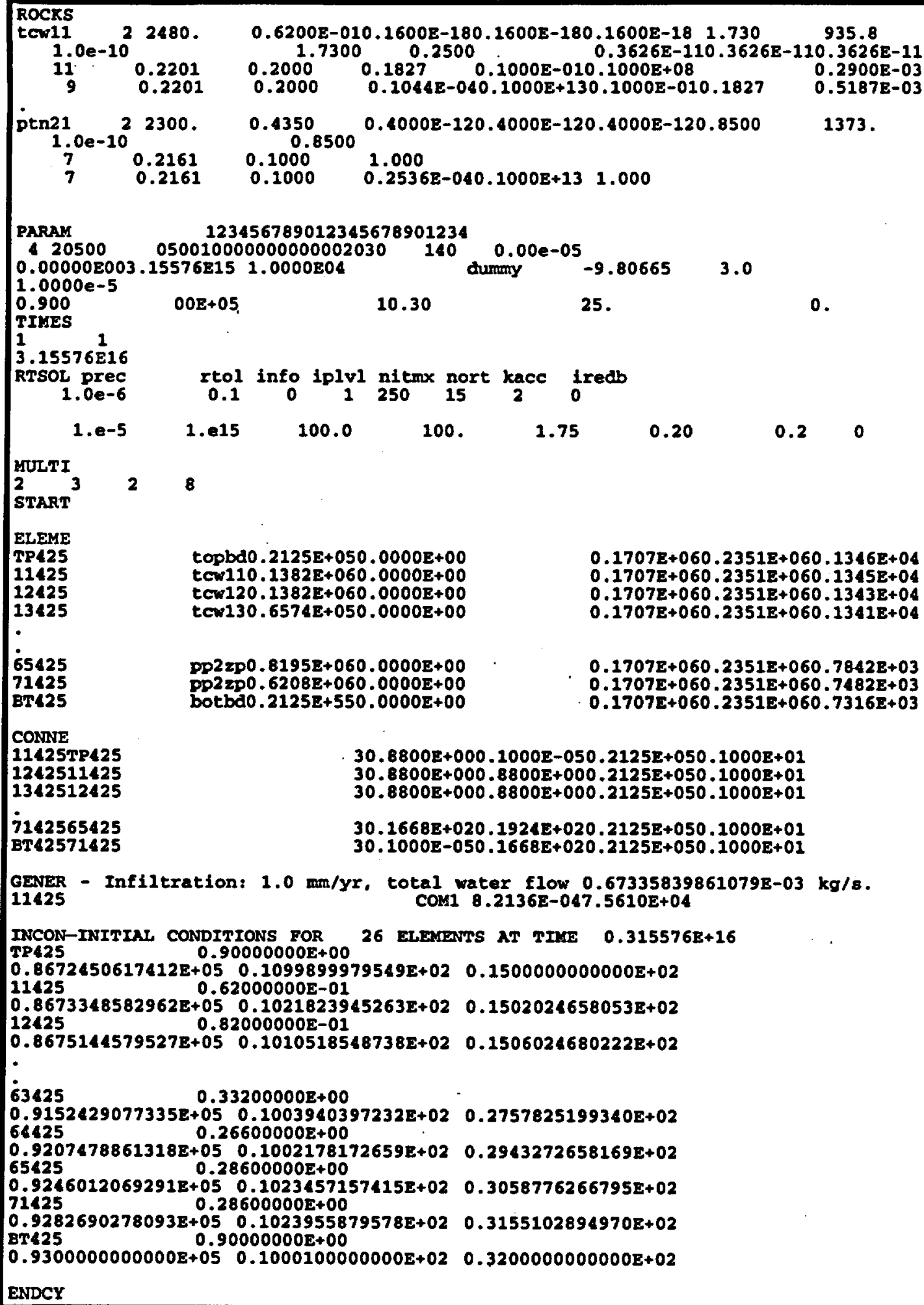

topbd0.2125E+050.0000E+00 tcw $110.1382 \mathrm{E}+060.0000 \mathrm{E}+00$ $\operatorname{tat} 120.1382 \mathrm{E}+060.0000 \mathrm{E}+00$ $\operatorname{tc} 130.6574 \mathrm{E}+050.0000 \mathrm{E}+00$

$002 z p 0.8195 \mathrm{E}+060.0000 \mathrm{E}+00$ $092=0.6208 \mathrm{E}+060.0000 \mathrm{E}+00$ botbao.2125E+550.0000E+00

$0.1707 E+060.2351 E+060.1346 \mathrm{E}+04$ $0.1707 E+060.2351 E+060.1345 E+04$ $0.1707 \mathrm{E}+060.2351 \mathrm{E}+060.1343 \mathrm{E}+04$ $0.1707 \mathrm{E}+060.2351 \mathrm{E}+060.1341 \mathrm{E}+04$

$0.1707 \mathrm{E}+060.2351 \mathrm{E}+060.7842 \mathrm{~B}+03$ $0.1707 \mathrm{E}+060.2351 \mathrm{E}+060.7482 \mathrm{E}+03$ $0.1707 \mathrm{E}+060.2351 \mathrm{E}+060.7316 \mathrm{E}+03$

GENER - Infiltration: $1.0 \mathrm{~mm} / \mathrm{yr}$, totel water flow $0.67335839861079 \mathrm{E}-03 \mathrm{~kg} / \mathrm{s}$.

11425 COM1 $8.2136 \mathrm{E}-047.5610 \mathrm{E}+04$

INCON-INITIAL CONDITIONS FOR 26 ELEMENS AT TIME $0.315576 \mathrm{~B}+16$

TP425 $0.90000000 \mathrm{E}+00$

$0.8672450617412 \mathrm{E}+05 \quad 0.1099899979549 \mathrm{z}+02 \quad 0.1500000000000 \mathrm{E}+02$

$11425 \quad 0.62000000 \mathrm{E}-01$

$0.8673348582962 \mathrm{E}+05 \quad 0.1021823945263 \mathrm{E}+02 \quad 0.1502024658053 \mathrm{E}+02$

$124250.82000000 \mathrm{E}-01$

$0.8675144579527 \mathrm{E}+05 \quad 0.1010518548738 \mathrm{E}+02 \quad 0.1506024680222 \mathrm{E}+02$

$63425 \quad 0.33200000 \mathrm{E}+00$

$0.9152429077335 \mathrm{E}+05 \quad 0.1003940397232 \mathrm{E}+02 \quad 0.2757825199340 \mathrm{E}+02$

$64425 \quad 0.26600000 z+00$

$0.9207478861318 \mathrm{E}+05 \quad 0.1002178172659 \mathrm{E}+02 \quad 0.2943272658169 \mathrm{E}+02$ $65425 \quad 0.28600000 \mathrm{E}+00$

$0.9246012069291 \mathrm{E}+05 \quad 0.1023457157415 \mathrm{E}+02 \quad 0.3058776266795 \mathrm{E}+02$

$714250.28600000 E+00$

$0.9282690278093 \mathrm{E}+050.1023955879578 \mathrm{E}+02 \quad 0.3155102894970 \mathrm{E}+02$

BT425 $0.90000000 \mathrm{E}+00$

$0.9300000000000 \mathrm{E}+05 \quad 0.1000100000000 \mathrm{E}+02 \quad 0.3200000000000 \mathrm{E}+02$

ENDCY

Figure 2. Input file for sample problem 1-D ECM formulation. 


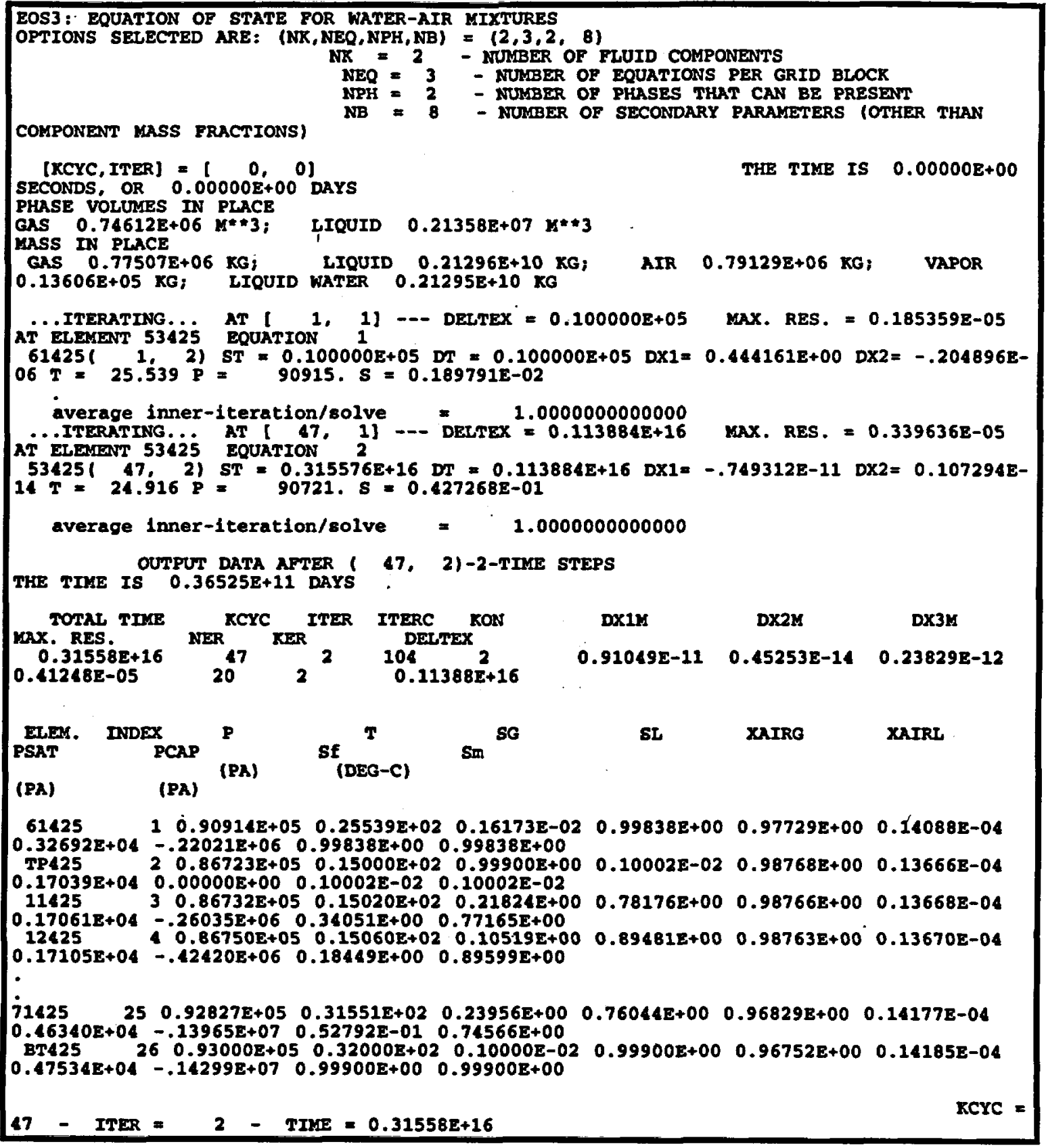

Figure 3. Selected output for sample problem 1. 


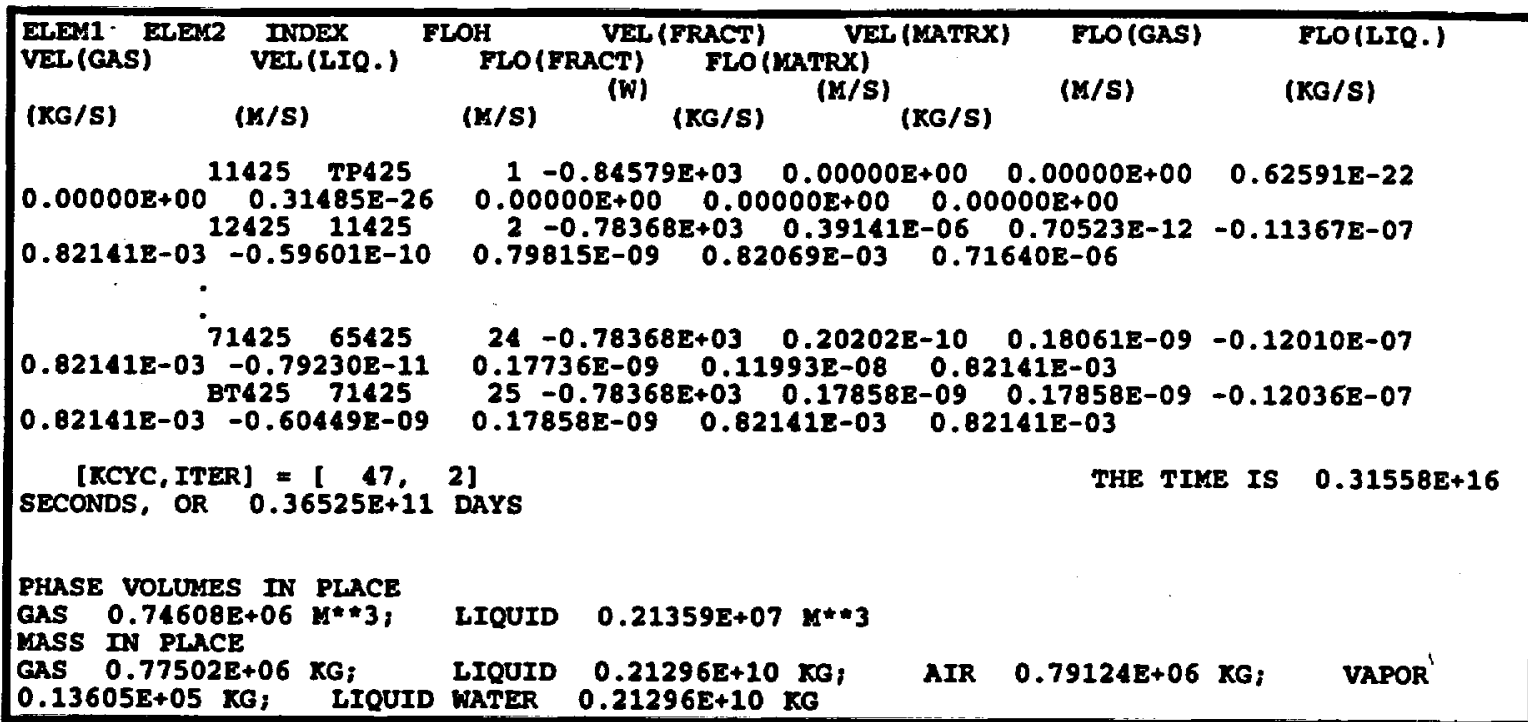

Figure 3. Selected output for sample problem 1 (contd.).

\begin{tabular}{|c|c|c|}
\hline Eleme & Pressure & Llq. Saturation \\
\hline & $\mathrm{Pa}$ & \\
\hline TP425 & $8.67 \mathrm{E}+04$ & $1.00 \mathrm{E}-03$ \\
\hline 11425 & $8.67 \mathrm{E}+04$ & $7.82 \mathrm{E}-01$ \\
\hline 12425 & $8.68 \mathrm{E}+04$ & $8.95 \mathrm{E}-01$ \\
\hline 63425 & $9.15 \mathrm{E}+04$ & $9.61 \mathrm{E}-01$ \\
\hline 64425 & $9.21 \mathrm{E}+04$ & $9.78 \mathrm{E}-01$ \\
\hline 65425 & $9.25 \mathrm{E}+04$ & $7.65 \mathrm{E}-01$ \\
\hline 71425 & $9.28 \mathrm{E}+04$ & $7.60 \mathrm{E}-01$ \\
\hline BT425 & $9.30 \mathrm{E}+04$ & $9.99 \mathrm{E}-01$ \\
\hline
\end{tabular}

Table 1. Steady-state pressure and liquid saturation profiles obtained using the modified version of the EOS3 module. 


\begin{tabular}{|c|c|c|}
\hline Eleme & Pressure & Llq. Saturation \\
\hline & Pa & \\
\hline TP425 & $8.67 \mathrm{E}+04$ & $1.00 \mathrm{E}-03$ \\
\hline 11425 & $8.67 \mathrm{E}+04$ & $7.82 \mathrm{E}-01$ \\
\hline 12425 & $8.68 \mathrm{E}+04$ & $8.95 \mathrm{E}-01$ \\
\hline 63425 & $9.15 \mathrm{E}+04$ & $9.61 \mathrm{E}-01$ \\
\hline 64425 & $9.21 \mathrm{E}+04$ & $9.78 \mathrm{E}-01$ \\
\hline 65425 & $9.25 \mathrm{E}+04$ & $7.65 \mathrm{E}-01$ \\
\hline 71425 & $9.28 \mathrm{E}+04$ & $7.60 \mathrm{E}-01$ \\
\hline BT425 & $9.30 \mathrm{E}+04$ & $9.99 \mathrm{E}-01$ \\
\hline
\end{tabular}

Table 2. Steady-state pressure and liquid saturation profiles obtained using the qualified version of the EOS3 module.

\begin{tabular}{|c|c|c|}
\hline Eleme & Eleme & Llquid flow rate \\
\hline & & $\mathrm{kg} / \mathrm{s}$ \\
\hline 12425 & 11425 & $8.21 \mathrm{E}-04$ \\
\hline 13425 & 12425 & $8.21 \mathrm{E}-04$ \\
\hline 63425 & 62425 & $8.21 \mathrm{E}-04$ \\
\hline 64425 & 63425 & $8.21 \mathrm{E}-04$ \\
\hline 65425 & 64425 & $8.21 \mathrm{E}-04$ \\
\hline 71425 & 65425 & $8.21 \mathrm{E}-04$ \\
\hline BT425 & 71425 & $8.21 \mathrm{E}-04$ \\
\hline
\end{tabular}

Table 3. Steady-state mass flow rate in $\mathrm{kg} / \mathrm{s}$ obtained using the modified version of the EOS3 module (ECM formulation).

\begin{tabular}{|c|c|c|}
\hline Eleme & Eleme & Llquid flow rate \\
\hline & & $\mathrm{kg} / \mathrm{s}$ \\
\hline 12425 & 11425 & $8.21 \mathrm{E}-04$ \\
\hline 13425 & 12425 & $8.21 \mathrm{E}-04$ \\
\hline 63425 & 62425 & $8.21 \mathrm{E}-04$ \\
\hline 64425 & 63425 & $8.21 \mathrm{E}-04$ \\
\hline 65425 & 64425 & $8.21 \mathrm{E}-04$ \\
\hline 71425 & 65425 & $8.21 \mathrm{E}-04$ \\
\hline BT425 & 71425 & $8.21 E-04$ \\
\hline
\end{tabular}

Table 4. Steady-state mass flow rate in $\mathrm{kg} / \mathrm{s}$ obtained using the qualified version of the EOS3 module (ECM formulation). 


\subsection{Sample problem 2:}

Input of spatially varying rock properties

Even though the qualified version of the EOS3/EOS9 modules has no restriction on the number of rock cards which assign heterogeneous parameters, practical applications of such approaches are limited due to requirement of computer storage and computational intensity for large field problems. Spatial variability of the different properties such as porosity and grain density is now being incorporated in the different conceptual models of flow and transport at Yucca Mountain. The inclusion of spatially variable rock properties in the TOUGH2 code is now facilitated through the use of SVPAR block in the input dataset (see Figure 4) and by needing an input file named svparam.dat for the porosity, grain density and specific heat of all the elements. The advantage of the additional data file is that the svparam.dat file could be generated thorugh the use of different geostatistical programs and the data file containing the spatial variability at different nodes could be directly read into the TOUGH2 code. Many other rock properties can be easily added to the input file if needed. An example of the svparam.dat is given in Table 5 and the output from the revised code and the qualified version is given in Tables 6 through 9 comparing the pressures and liquid saturations at steady-state conditions as well as liquid fluxes using the ECM EOS3 module.

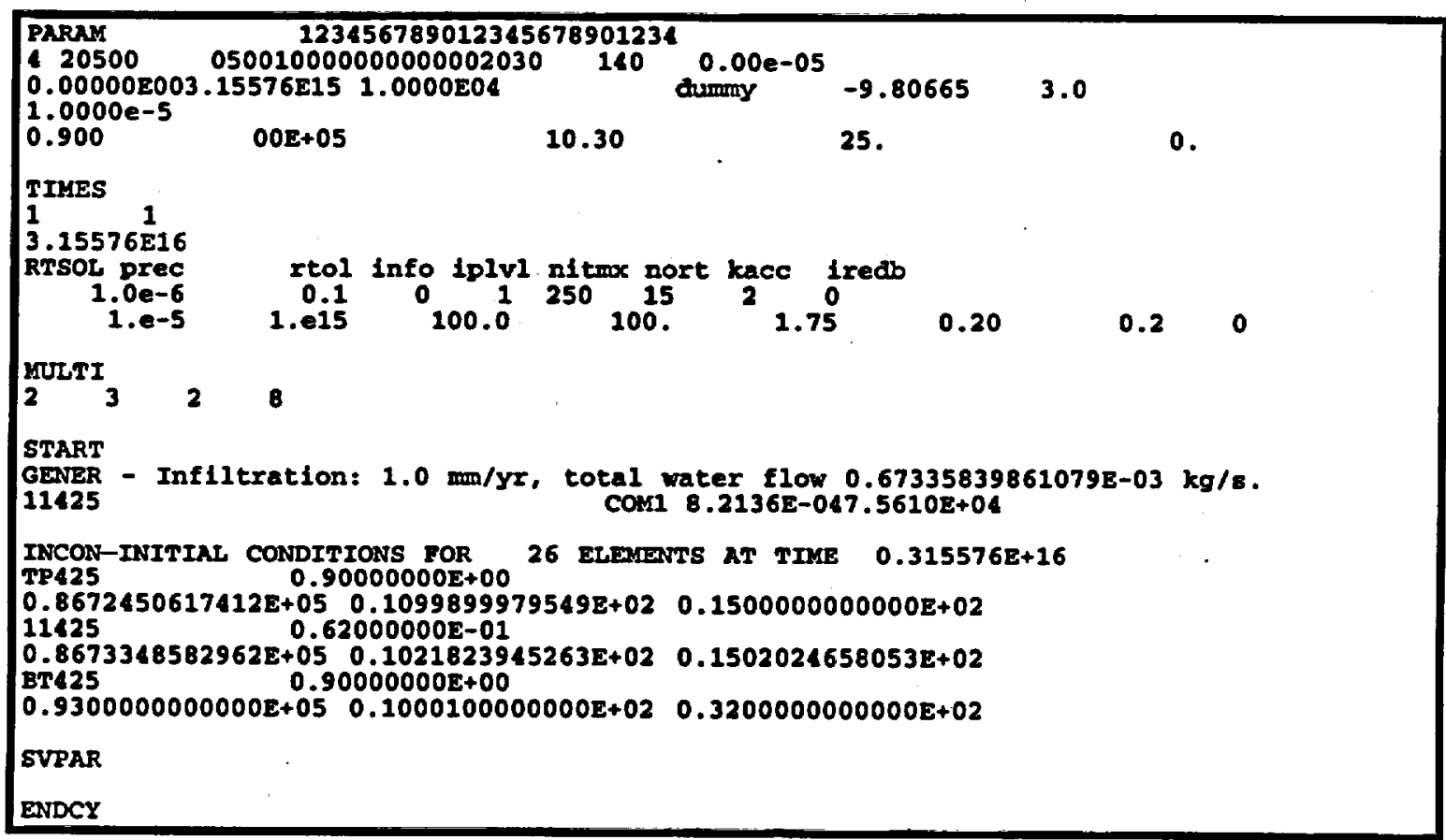

Figure 4. Input file for spatially varying parameters (sample problem 2). 


\begin{tabular}{|r|rrr|}
\hline Rock & Porosity & $\begin{array}{c}\text { Denslty } \\
\mathrm{kg} / \mathrm{m}^{3}\end{array}$ & $\begin{array}{l}\text { Sp.heat } \\
\text { J/kg }\end{array}$ \\
\hline topbd $\mathrm{C}$ & \\
\hline tcw11 & $6.20 \mathrm{E}-02$ & 2480 & 1.73 \\
\hline tcw12 & $8.20 \mathrm{E}-02$ & 2480 & 1.73 \\
\hline tsw35 & 0.13 & 2480 & 1.73 \\
\hline pp2zp & 0.286 & 2300 & 1.56 \\
\hline pp2zp & 0.286 & 2300 & 1.56 \\
\hline botbd & 0.9 & 2300 & 1.56 \\
\hline
\end{tabular}

Table 5. Example of the svparam.dat file where the porosity has been varied between the different rock types and/or model layers.

\begin{tabular}{|c|c|c|}
\hline Eleme & Pressure & Llq. Saturation \\
\hline & $\mathrm{Pa}$ & \\
\hline TP425 & $8.67 E+04$ & 1.0002E-03 \\
\hline 11425 & 8.67E+04 & 7.8176E-01 \\
\hline 12425 & $8.68 E+04$ & $8.9481 E-01$ \\
\hline 13425 & 8.68E+04 & 8.7.941E-01 \\
\hline 63425 & $0.15 E+04$ & $9.6060 \mathrm{E}-01$ \\
\hline 64425 & $9.21 E+04$ & 9.7822E-01 \\
\hline 65425 & $9.25 E+04$ & 7.6543E-01 \\
\hline 71425 & $0.28 E+04$ & 7.6044E-01 \\
\hline BT425 & $9.30 E+04$ & $9.9900 \mathrm{E}-01$ \\
\hline
\end{tabular}

Table 6. Steady-state pressure and liquid saturation profiles obtained using the modified version of the EOS3 module where the spatially varying rock properties are input through the svparam.dat.

\begin{tabular}{|c|c|c|}
\hline Eleme & Pressure & Llq. Saturation \\
\hline & Pa & \\
\hline TP425 & $8.67 E+04$ & $1.0002 E-03$ \\
\hline 11425 & $8.67 E+04$ & $7.8176 E-01$ \\
\hline 12425 & $8.68 E+04$ & $8.9481 E-01$ \\
\hline 13425 & $8.68 E+04$ & $8.7941 E-01$ \\
\hline 63425 & $9.15 E+04$ & $9.6060 E-01$ \\
\hline 64425 & $9.21 E+04$ & $9.7822 E-01$ \\
\hline 65425 & $9.25 E+04$ & $7.6543 E-01$ \\
\hline 71425 & $9.28 E+04$ & $7.6044 E-01$ \\
\hline BT425 & $9.30 E+04$ & $9.9900 E-01$ \\
\hline
\end{tabular}

Table 7. Steady-state pressure and liquid saturation profiles obtained using the qualified version of the EOS3 module where the ROCKS block is used to input the varying porosities. 


\begin{tabular}{|c|c|c|}
\hline Eleme & Eleme & Llquid Flow Rate \\
\hline & & $\mathrm{kg} / \mathrm{s}$ \\
\hline 12425 & 11425 & $8.2141 E-04$ \\
\hline 13425 & 12425 & $8.2141 E-04$ \\
\hline 21425 & 13425 & $8.2141 E-04$ \\
\hline 63425 & 62425 & $8.2141 E-04$ \\
\hline 64425 & 63425 & $8.2141 E-04$ \\
\hline 65425 & 64425 & $8.2141 E-04$ \\
\hline 71425 & 65425 & $8.2141 E-04$ \\
\hline BT425 & 71425 & B.2141E-04 \\
\hline
\end{tabular}

Table 8. Steady-state mass flow rate in $\mathrm{kg} / \mathrm{s}$ obtained using the modified version of the EOS3 module where svparam.dat is used to input the varying properties.

\begin{tabular}{|c|c|c|}
\hline Eleme & Eleme & Llquid Flow Rate \\
\hline & & $\mathrm{kg} / \mathrm{s}$ \\
\hline 12425 & 11425 & $8.2141 \mathrm{E}-04$ \\
\hline 13425 & 12425 & $8.2141 \mathrm{E}-04$ \\
\hline 21425 & 13425 & $8.2141 \mathrm{E}-04$ \\
\hline 63425 & 62425 & $8.2141 \mathrm{E}-04$ \\
\hline 64425 & 63425 & $8.2141 \mathrm{E}-04$ \\
\hline 65425 & 64425 & $8.2141 \mathrm{E}-04$ \\
\hline 71425 & 65425 & $8.2141 \mathrm{E}-04$ \\
\hline BT425 & 71425 & $8.2141 \mathrm{E}-04$ \\
\hline
\end{tabular}

Table 9. Steady-state mass flow rate in $\mathrm{kg} / \mathrm{s}$ obtained using the qualified version of the EOS3 module.

\subsection{Dual permeabllity formulation with various interface area reduction factor}

A series of sample problems using the various options for modifying the interface area between matrix and fracture is developed. The results are shown for EOS9 module but a identical procedure and subroutines are used for the EOS3 and T2R3D module too. The problem consists of a one-dimensional vertical grid with 45 non-uniform fracture and matrix elements, and 65 connections. This is a one-dimensional vertical moisture flow problem under two-phase and isothermal conditions. The bottom boundary element is set to constant liquid saturation by specifying a large volume. The second element from the top element is subjected to a constant water infiltration.

\subsubsection{Sample problem 3: ISOT $=-1$}

ISOT $=-1$ leads to reduction in the fracture-matrix interconnection area by the fraction of the upstream block liquid saturation in the dual-permeability model. 
The methodology selected to compare the results between the revised code and the earlier version of the code is to obtain the steady-state condition using the revised version of the code by selecting the appropriate ISOT value (for example ISOT=-1 in Figure 5). This corresponds to the case of modifying the interface area by the upstream liquid saturation. From the results of the EOS9 module (Figure 6), the appropriate value of the liquid saturation in two blocks (Fj425/Mj425 and Fk425/Mk425) are selected based on the capillary pressure values in the fracture/matrix blocks. The interface area in the input file is accordingly modified. The interface area for the Fj425/Mj425 connection is reduced from $0.3491 E+06$ to $0.3729 \mathrm{E}+04 \mathrm{~m}^{2}$ and the corresponding reduction for the connection Fk425/Mk425 is from 0.4769E+06 to 0.5129E+04 $\mathrm{m}^{2}$ in the CONNE block in Figure 6 . The qualified version of the code is then run with the input file as shown in Figure 7.

For the different cases considered here, we compare the pressure and the liquid saturation in the individual matrix and fracture elements (identified with $M$ and $F$, respectively). Model elements are also labeled alphabetically with a lower case letter $(\mathrm{Ma} / \mathrm{Fa})$ starting from the surface. The element name also contains the map view element number. The input file for this problem is shown in Figure 5 and a section of the output file is given in Figure 6. The results are presented after 100 time steps $(0.510221 \mathrm{E}+13 \mathrm{sec})$ in Tables 10 to 13. Also compared are the mass flow rates across different interfaces as shown below.

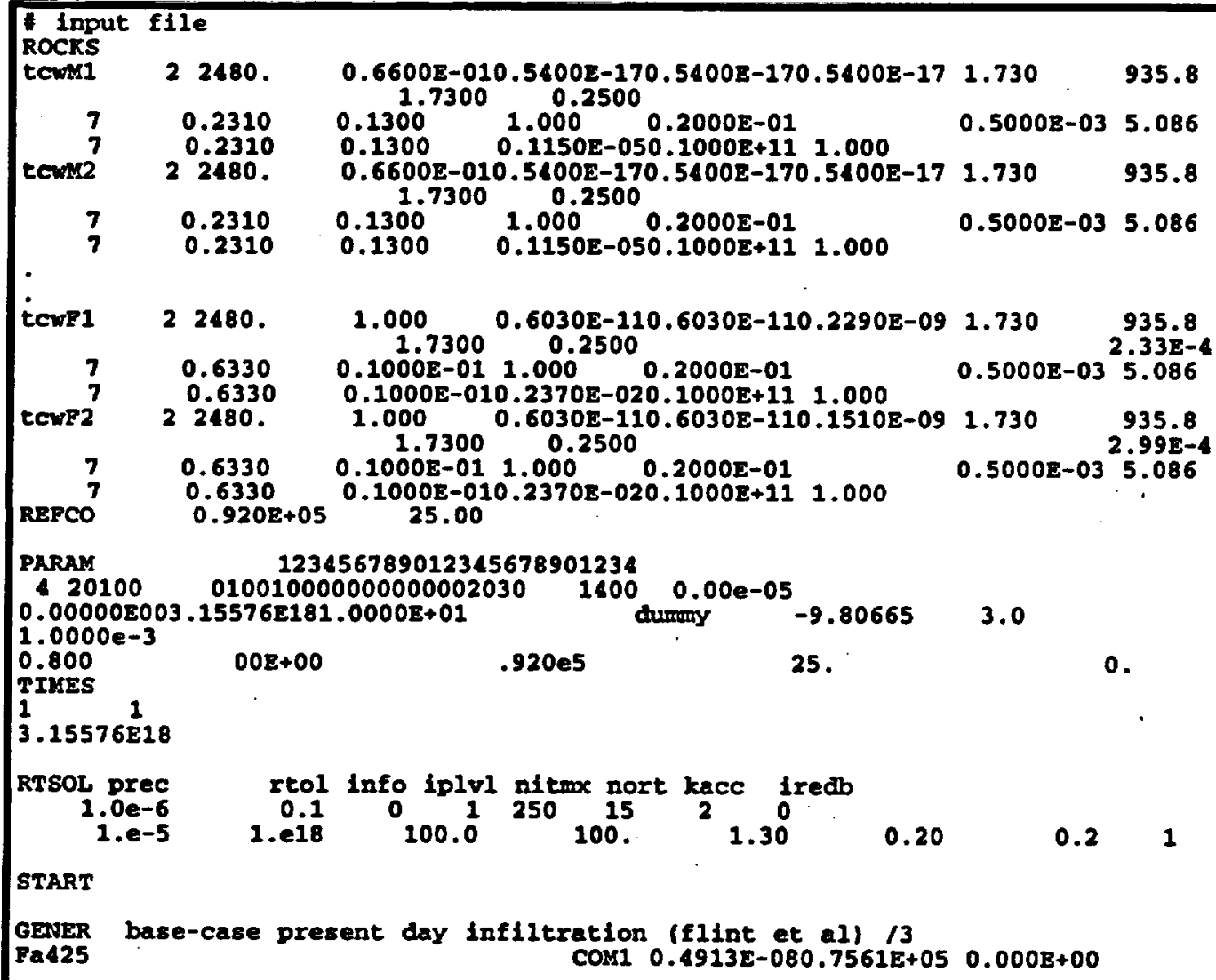

Figure 5. Input file for sample problem 3 - Dual-permeability EOS9, ISOT $=-1$. 


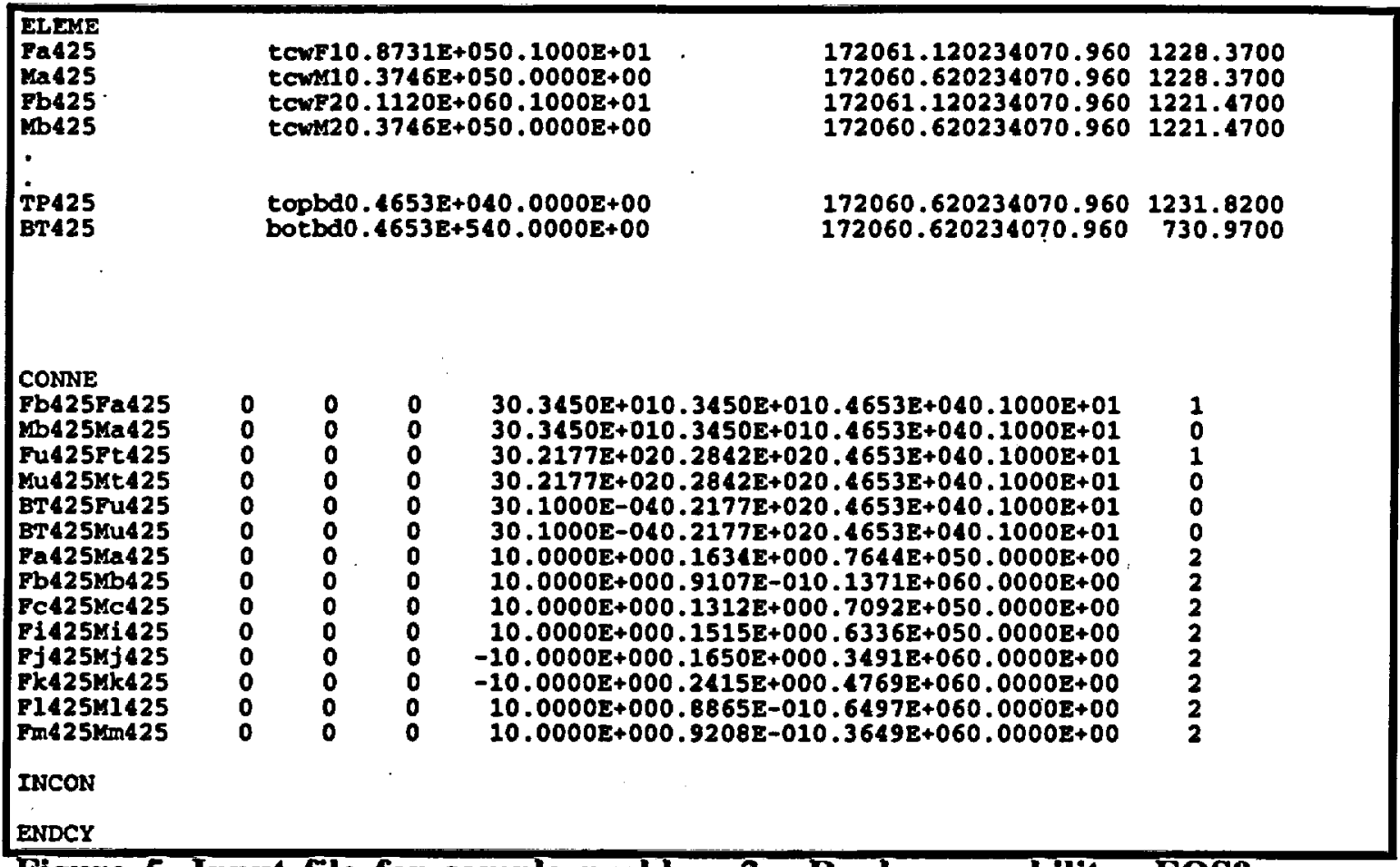

Figure 5. Input file for sample problem 3-Dual-permeability EOS9, ISOT $=-1$ (contd.).

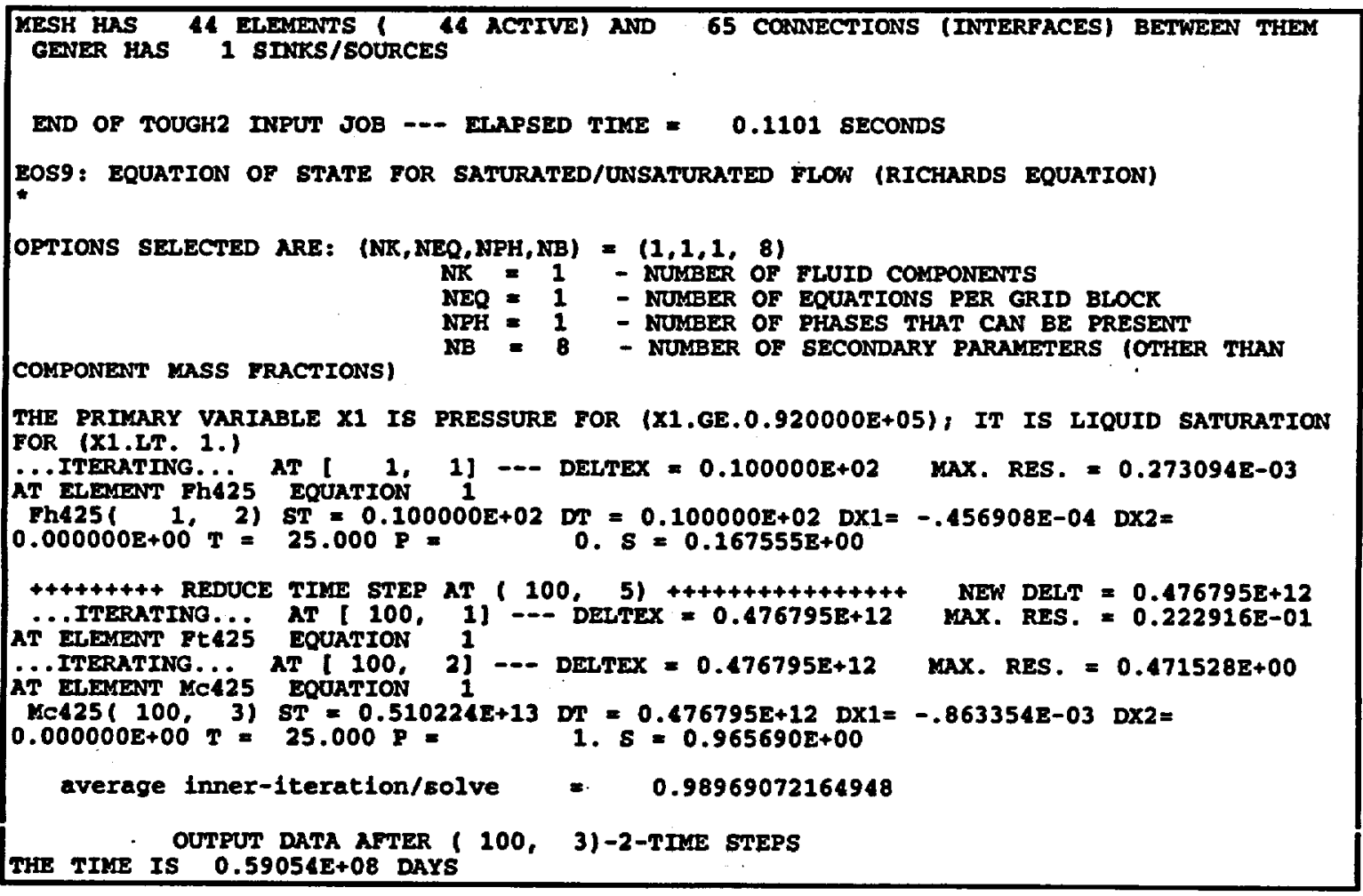

Figure 6. Selected output for sample problem 3. 


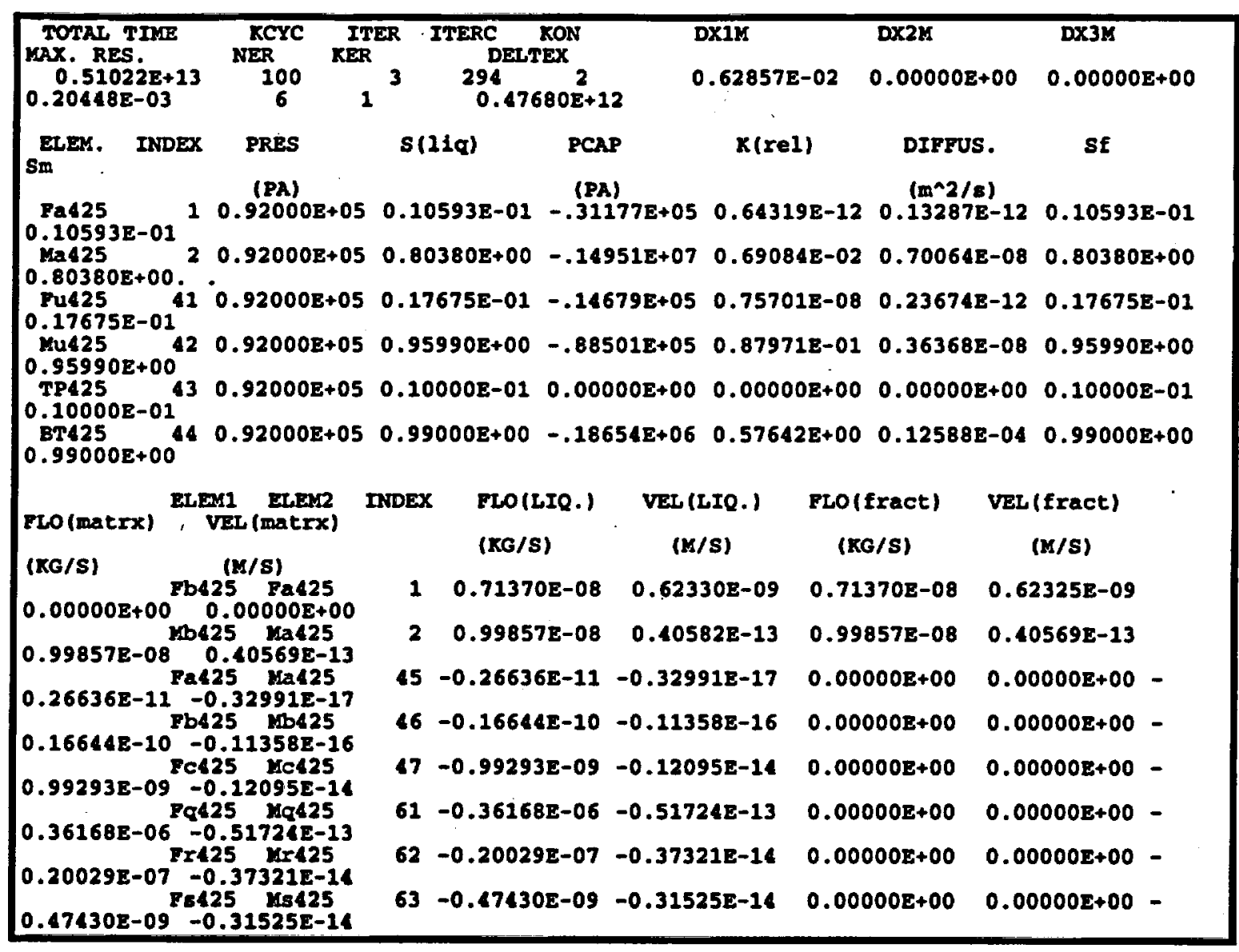

Figure 6. Selected output for sample problem 3 (contd.).

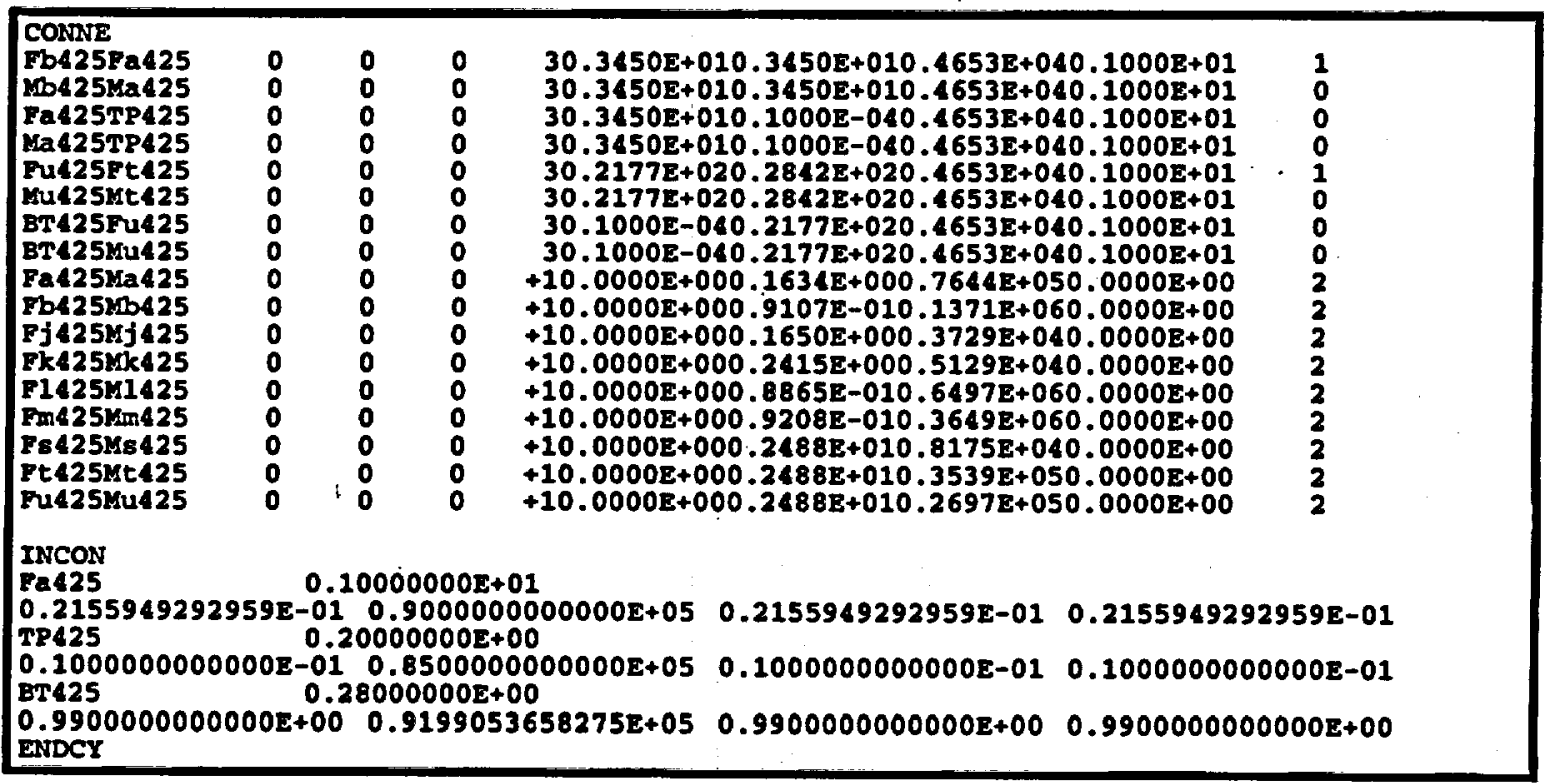

Figure 7. Selected input to the qualified version of EOS9 for sample problem 3. 


\begin{tabular}{|c|c|c|}
\hline Eleme & Pressure & Liq. S \\
\hline & $\mathrm{Pa}$ & \\
\hline TP425 & $9.20 E+04$ & $1.0000 E-02$ \\
\hline Fa425 & $9.20 E+04$ & 1.0593E-02 \\
\hline Ma425 & $9.20 E+04$ & $8.0380 E-01$ \\
\hline F1425 & $9.20 E+04$ & 1.0271E-02 \\
\hline Mi425 & $9.20 E+04$ & $7.7399 E-01$ \\
\hline F/425 & $9.20 E+04$ & $1.0681 E-02$ \\
\hline M/425 & $9.20 E+04$ & 4.6075E-01 \\
\hline Fk425 & $9.20 E+04$ & 1.0755E-02 \\
\hline Mk425 & $9.20 E+04$ & 5.9422E-01 \\
\hline F1425 & $9.20 E+04$ & 1.1531E-02 \\
\hline$M / 425$ & $9.20 E+04$ & $8.3896 E-01$ \\
\hline Fm 425 & $9.20 E+04$ & $1.2944 E-02$ \\
\hline $\mathrm{Mm425}$ & $9.20 E+04$ & 6.8779E-01 \\
\hline BT425 & $9.20 E+04$ & $9.9000 E-01$ \\
\hline
\end{tabular}

Table 10. Pressure and liquid saturation profiles obtained using the modified version of the EOS9 module after 100 timesteps (ISOT=-1).

\begin{tabular}{|l|c|c|}
\hline Eleme & Pressure & Llq. Saturation \\
\hline & Pa & \\
\hline TP425 & $9.20 E+04$ & $1.0000 E-02$ \\
\hline Fa425 & $9.20 E+04$ & $1.0593 E-02$ \\
\hline$M a 425$ & $9.20 E+04$ & $8.0380 E-01$ \\
\hline FI425 & $9.20 E+04$ & $1.0271 E-02$ \\
\hline$M \mid 425$ & $9.20 E+04$ & $7.7399 E-01$ \\
\hline FI425 & $9.20 E+04$ & $1.0681 E-02$ \\
\hline$M \mid 425$ & $9.20 E+04$ & $4.6075 E-01$ \\
\hline FK425 & $9.20 E+04$ & $1.0755 E-02$ \\
\hline$M k 425$ & $9.20 E+04$ & $5.9422 E-01$ \\
\hline FI425 & $9.20 E+04$ & $1.1531 E-02$ \\
\hline$M \mid 425$ & $9.20 E+04$ & $8.3896 E-01$ \\
\hline Fm425 & $9.20 E+04$ & $1.2944 E-02$ \\
\hline$M m 425$ & $9.20 E+04$ & $6.8779 E-01$ \\
\hline BT425 & $9.20 E+04$ & $9.9000 E-01$ \\
\hline
\end{tabular}

Table 11. Pressure and liquid saturation profiles obtained using the qualified version of the EOS9 module after 100 timesteps (ISOT=-1). 


\begin{tabular}{|c|c|c|}
\hline Eleme & Eleme & Llquid flow rate \\
\hline & & $\mathrm{kg} / \mathrm{s}$ \\
\hline Fb425 & Fa425 & 7.1370E-09 \\
\hline Mb425 & Ma425 & 0.9857 E-09 \\
\hline Fi425 & Fh425 & $3.5477 E-15$ \\
\hline Mi425 & Mh425 & $4.4578 E-07$ \\
\hline F/425 & F1425 & $5.7607 E-10$ \\
\hline$M / 425$ & Mi425 & 4.5473E-07 \\
\hline Fk425 & Fi425 & $1.3434 \mathrm{E}-08$ \\
\hline Mk425 & Mi425 & $7.2127 \mathrm{E}-07$ \\
\hline FI425 & Fk425 & $3.6757 E-08$ \\
\hline M1425 & Mk425 & 1.3346E-06 \\
\hline Fm425 & $F 1425$ & 6.3383E-08 \\
\hline$M m 425$ & M1425 & $1.4908 \mathrm{E}-06$ \\
\hline Fi425 & Mi425 & $-8.9538 E-13$ \\
\hline Fl425 & Mi425 & $-2.3578 E-12$ \\
\hline Fk425 & Mk425 & $-5.4393 E-13$ \\
\hline$F / 425$ & M1425 & $-1.0201 \mathrm{E}-00$ \\
\hline Fm425 & Mm425 & $-2.8863 E-08$ \\
\hline
\end{tabular}

Table 12. Liquid flow rate in $\mathrm{kg} / \mathrm{s}$ obtained using the modified version of the EOS9 module after 100 timesteps (ISOT $=-1$ ).

\begin{tabular}{|c|c|c|}
\hline Ele & Eleme & Llquid flow rate \\
\hline & & $\mathrm{kg} / \mathrm{s}$ \\
\hline Fb425 & $F_{a 425}$ & $0.71371 E-08$ \\
\hline Mb425 & Ma425 & $0.89852 E-08$ \\
\hline F1425 & Fh425 & $0.35472 E-14$ \\
\hline Mi425 & Mh425 & $0.44576 E-06$ \\
\hline F1425 & Fi425 & 0.57608 E-08 \\
\hline M/425 & Mi425 & $0.45471 E-06$ \\
\hline Fk425 & F/425 & $0.13434 E-07$ \\
\hline Mk425 & M/425 & $0.72123 E-06$ \\
\hline FI425 & Fk425 & $0.36758 E-07$ \\
\hline M1425 & Mk425 & $0.13345 E-05$ \\
\hline Fm425 & FI425 & $0.63383 E-07$ \\
\hline Mm425 & $M / 425$ & $0.14807 E-05$ \\
\hline Fi425 & $M 1425$ & $-0.89542 E-12$ \\
\hline$F / 425$ & MI425 & $-0.23580 E-11$ \\
\hline Fk425 & Mk425 & $-5.43960 E-13$ \\
\hline F1425 & MI425 & $-1.02010 E-09$ \\
\hline Fm425 & Mm425 & $-2.98640 E-08$ \\
\hline
\end{tabular}

Table 13. Liquid flow rate in $\mathrm{kg} / \mathrm{s}$ obtained using the qualified version of the EOS9 module after 100 timesteps (ISOT=-1). 


\subsubsection{Sample problem 4: ISOT $=-3$}

The reduction factor is the product of upstream relative permeability times a constant factor. The constant factor is input in the field RP(7) for each rock type of fractures where $R P(I), I=1,7$ are the various input data for relative permeability function given in the card ROCKS.1.2 (see Pruess, 1987 for details of input formats). The results are reported after a total time of $0.510224 \mathrm{E}+13$ seconds in Tables 14 to 17.

\begin{tabular}{|l|c|c|}
\hline Eleme & Pressure & LIq. Saturation \\
\hline & Pa & \\
\hline TP425 & $9.20 E+04$ & $1.0000 E-02$ \\
\hline Fa425 & $9.20 E+04$ & $1.0593 E-02$ \\
\hline Ma425 & $9.20 E+04$ & $8.0379 E-01$ \\
\hline Fi425 & $9.20 E+04$ & $1.0271 E-02$ \\
\hline Mi425 & $9.20 E+04$ & $7.7399 E-01$ \\
\hline Fi425 & $9.20 E+04$ & $1.0681 E-02$ \\
\hline$M \mid 425$ & $9.20 E+04$ & $4.6074 E-01$ \\
\hline FK425 & $9.20 E+04$ & $1.0755 E-02$ \\
\hline$M k 425$ & $9.20 E+04$ & $5.9422 E-01$ \\
\hline FI425 & $9.20 E+04$ & $1.1531 E-02$ \\
\hline$M \mid 425$ & $9.20 E+04$ & $8.3896 E-01$ \\
\hline Fm425 & $9.20 E+04$ & $1.2944 E-02$ \\
\hline Mm425 & $9.20 E+04$ & $6.8779 E-01$ \\
\hline BT425 & $9.20 E+04$ & $9.9000 E-01$ \\
\hline
\end{tabular}

Table 14. Pressure and liquid saturation profiles obtained using the modified version of the EOS9 module after 100 timesteps (ISOT=-3).

\begin{tabular}{|c|c|c|}
\hline Eleme & Pressure & Llq. Saturation \\
\hline & $\mathrm{Pa}$ & \\
\hline$T P_{425}$ & $9.20 E+04$ & 1.0000 E-02 \\
\hline $\mathrm{Fa425}$ & $9.20 E+04$ & $1.0593 E-02$ \\
\hline Ma425 & $9.20 E+04$ & $8.0379 E-01$ \\
\hline $\mathrm{Fl} 425$ & $9.20 E+04$ & $1.0271 E-02$ \\
\hline Mi425 & $9.20 E+04$ & 7.7399E-01 \\
\hline F/425 & $9.20 E+04$ & $1.0681 \mathrm{E}-02$ \\
\hline$M / 425$ & 9.20E+04 & 4.60 \\
\hline Fk425 & $9.20 E+04$ & 1.07 \\
\hline Mk425 & $9.20 E+04$ & 5.9422E-01 \\
\hline F1425 & $9.20 E+04$ & $1.1531 E-02$ \\
\hline M/425 & $9.20 E+04$ & $8.3896 E-01$ \\
\hline Fm425 & $9.20 E+04$ & 1.2944E-02 \\
\hline Mm425 & $9.20 E+04$ & 6.8779E-01 \\
\hline BT425 & $0.20 E+04$ & 9.8000 E-01 \\
\hline
\end{tabular}

Table 15. Pressure and liquid saturation profiles obtained using the qualified version of the EOS9 module after 100 timesteps (ISOT=-3). 


\begin{tabular}{|c|c|c|}
\hline Eleme & Eleme & Liquid flow rate \\
\hline & & $\mathrm{kg} / \mathrm{s}$ \\
\hline Fb425 & Fa425 & $0.71370 E-08$ \\
\hline Mb425 & Ma425 & $0.99849 E-08$ \\
\hline Fi425 & Fh425 & $10.35468 E-14$ \\
\hline$M 1425$ & Mh425 & $0.44574 E-06$ \\
\hline Fi425 & Fi425 & $0.57607 E-09$ \\
\hline M1425 & Mi425 & $0.45469 E-06$ \\
\hline Fk425 & Fi425 & $0.13437 E-07$ \\
\hline Mk425 & Mi425 & $0.72119 \mathrm{E}-06$ \\
\hline F/425 & Fk425 & $0.36761 E-07$ \\
\hline M1425 & Mk425 & $0.13345 E-05$ \\
\hline Fi425 & M1425 & $-0.89543 E-12$ \\
\hline F/425 & M/425 & $-0.12036 E-20$ \\
\hline Fk425 & Mk425 & $-0.40125 E-21$ \\
\hline FI425 & M1425 & $-0.10202 E-08$ \\
\hline
\end{tabular}

Table 16. Liquid flow rate in $\mathrm{kg} / \mathrm{s}$ obtained using the modified version of the EOS9 module after $0.510224 \mathrm{E}+13$ sec (ISOT=-3).

\begin{tabular}{|c|c|c|}
\hline Eleme & Eleme & Llquid flow rate \\
\hline & & $\mathrm{kg} / \mathrm{s}$ \\
\hline Fb425 & Fa425 & 0.71370E-08 \\
\hline Mb425 & Ma425 & $0.99849 E-08$ \\
\hline F1425 & Fh425 & $0.35468 E-14$ \\
\hline Mi425 & Mh425 & $0.44574 E-06$ \\
\hline$F / 425$ & F1425 & 0.57607.E-09 \\
\hline$M / 425$ & $M 1425$ & $0.45469 E-06$ \\
\hline Fk425 & Fi425 & $0.13437 E-07$ \\
\hline Mk425 & M/425 & $0.72119 E-06$ \\
\hline F1425 & Fk425 & $0.36761 E-07$ \\
\hline$M 1425$ & Mk425 & $0.13345 E-05$ \\
\hline F1425 & Mi425 & $-0.89543 E-12$ \\
\hline$F / 425$ & Mi425 & $-0.12036 E-20$ \\
\hline Fk425 & Mk425 & $-0.40125 E-21$ \\
\hline FI425 & $M / 425$ & $-0.10202 E-08$ \\
\hline
\end{tabular}

Table 17. Liquid flow rate in $\mathrm{kg} / \mathrm{s}$ obtained using the qualified version of the EOS9 module after $0.510224 \mathrm{E}+13 \mathrm{sec}$ (ISOT $=-3$ ). 


\subsubsection{Sample problem 5: ISOT $=-4$}

For ISOT $=-4$, the reduction factor equal to relative permeability to liquid of the upstream block in the fracture-matrix dual-permeability connection as outlined by Ho (1997). The steady-state results for the 1-D column are presented in Tables 18 to 21 .

\begin{tabular}{|l|c|c|}
\hline Eleme & Pressure & Llq. Saturation \\
\hline & Pa & \\
\hline TP425 & $9.20 E+04$ & $1.0000 E-02$ \\
\hline Fa425 & $9.20 E+04$ & $2.2280 E-02$ \\
\hline Ma425 & $9.20 E+04$ & $9.4198 E-01$ \\
\hline Fl425 & $9.20 E+04$ & $1.0550 E-02$ \\
\hline Mi425 & $9.20 E+04$ & $9.8191 E-01$ \\
\hline Fl425 & $9.20 E+04$ & $1.1722 E-02$ \\
\hline MI425 & $9.20 E+04$ & $9.1104 E-01$ \\
\hline Fk425 & $9.20 E+04$ & $1.7061 E-02$ \\
\hline MK425 & $9.20 E+04$ & $9.9376 E-01$ \\
\hline Fl425 & $9.20 E+04$ & $2.5333 E-02$ \\
\hline MI425 & $9.20 E+04$ & $9.9949 E-01$ \\
\hline Fm425 & $9.20 E+04$ & $3.4990 E-02$ \\
\hline Mm425 & $9.20 E+04$ & $9.7740 E-01$ \\
\hline BT425 & $9.20 E+04$ & $9.9000 E-01$ \\
\hline
\end{tabular}

Table 18. Steady-state pressure and liquid saturation profiles obtained using the modified version of the EOS9 module (ISOT=-4).

\begin{tabular}{|c|c|c|}
\hline Eleme & Pressure & Llq. Saturation \\
\hline & $\mathrm{Pa}$ & \\
\hline TP425 & $9.20 E+04$ & $1.0000 \mathrm{E}-02$ \\
\hline Fa425 & $9.20 E+04$ & $2.2280 \mathrm{E}-02$ \\
\hline Ma425 & $8.20 E+04$ & 8.4198E-01 \\
\hline FI425 & $8.20 E+04$ & $1.0550 \mathrm{E}-02$ \\
\hline Mi425 & $9.20 E+04$ & $9.8191 \mathrm{E}-01$ \\
\hline FI425 & $9.20 E+04$ & $1.1722 \mathrm{E}-02$ \\
\hline M1425 & $9.20 E+04$ & $8.1104 \mathrm{E}-01$ \\
\hline Fk425 & $8.20 E+04$ & $1.7061 \mathrm{E}-02$ \\
\hline Mk425 & $9.20 E+04$ & $9.9376 \mathrm{E}-01$ \\
\hline FI425 & $9.20 E+04$ & $2.5333 \mathrm{E}-02$ \\
\hline MI425 & $9.20 \mathrm{E}+04$ & $9.9849 \mathrm{E}-01$ \\
\hline Fm425 & $9.20 E+04$ & $3.4880 \mathrm{E}-02$ \\
\hline Mm425 & $9.20 E+04$ & $9.7740 E-01$ \\
\hline BT425 & $9.20 E+04$ & $9.8000 E-01$ \\
\hline
\end{tabular}

Table 19. Steady-state pressure and liquid saturation profiles obtained using the qualified version of the EOS9 module (ISOT=-4). 


\begin{tabular}{|c|c|c|}
\hline Eleme & Eleme & Llquild flow rate \\
\hline & & $\mathrm{kg} / \mathrm{s}$ \\
\hline Fb425 & Fa425 & $0.49125 E-03$ \\
\hline Mb425 & Ma425 & $0.45572 E-07$ \\
\hline Fi425 & Fh425 & $0.39063 E-11$ \\
\hline Mi425 & Mh425 & $0.49130 \mathrm{E}-03$ \\
\hline Fi425 & FI425 & $0.79352 E-08$ \\
\hline M/425 & Mi425 & $0.49129 E-03$ \\
\hline Fk425 & Fi425 & $0.39500 E-06$ \\
\hline Mk425 & M/425 & $0.49090 \mathrm{E}-03$ \\
\hline F1425 & Fk425 & $0.13028 E-03$ \\
\hline MI425 & Mk425 & $0.36102 E-03$ \\
\hline Fm 425 & F1425 & $0.30854 E-03$ \\
\hline Mm425 & M1425 & $0.18276 \mathrm{E}-03$ \\
\hline Fi425 & Mi425 & $0.79313 E-08$ \\
\hline F $\lcm{425}$ & M/425 & $0.38707 E-06$ \\
\hline Fk425 & Mk425 & 1.29880 E-04 \\
\hline F1425 & M1425 & 1.78260E-04 \\
\hline Fm425 & Mm425 & $-3.6355 E-06$ \\
\hline
\end{tabular}

Table 20. Steady-state liquid flow rate in $\mathrm{kg} / \mathrm{s}$ obtained using the modified version of the EOS9 module (ISOT=-4).

\begin{tabular}{|c|c|c|}
\hline Eleme & Eleme & Llquild flow rate \\
\hline & & $\mathrm{kg} / \mathrm{s}$ \\
\hline Fb425 & Fa425 & $0.48125 E-03$ \\
\hline Mb425 & Ma425 & $0.45572 E-07$ \\
\hline F1425 & Fh425 & $0.39063 E-11$ \\
\hline M1425 & Mh425 & 0.49130 E- 03 \\
\hline F/425 & Fi425 & $0.79352 E-08$ \\
\hline M/425 & M1425 & $0.49129 E-03$ \\
\hline Fk425 & FI425 & $0.39500 E-06$ \\
\hline Mk425 & M/425 & $0.49090 \mathrm{E}-03$ \\
\hline FI425 & Fk425 & $0.13028 E-03$ \\
\hline MI425 & Mk425 & $0.36102 E-03$ \\
\hline Fm 425 & Fl425 & $0.30854 \mathrm{E}-03$ \\
\hline Mm425 & M1425 & $0.18276 E-03$ \\
\hline Fi425 & M1425 & $0.79313 E-08$ \\
\hline F]425 & MJ425 & $0.38707 E-06$ \\
\hline Fk425 & Mk425 & 1.29880 E-04 \\
\hline FI425 & MI425 & $1.78260 \mathrm{E}-04$ \\
\hline Fm 425 & Mm425 & $-3.6355 E-06$ \\
\hline
\end{tabular}

Table 21. Steady-state liquid flow rate in $\mathrm{kg} / \mathrm{s}$ obtained using the qualified version of the EOS9 module (ISOT=-4). 


\subsubsection{Sample problem 6: ISOT $=-7$}

For ISOT=-7; the reduction factor for the fracture-matrix interface area is the normalized mass flux $\left(f_{m}\right)$ through fractures given by the following relation $f_{m}=q / q_{1-d}$ where $q_{f}$ is the maximum mass flux through the fractures, defined as fracture mass flux under unit vertical hydraulic gradient, and $q_{1-1}$ is a normalized factor, input by the user. The results are reported after a total time of $0.510224 \mathrm{E}+13$ seconds in Tables 22 to 25 .

\begin{tabular}{|l|c|c|}
\hline Eleme & Pressure & Liq. Saturation \\
\hline & Pa & \\
\hline TP425 & $9.20 E+04$ & $1.0000 E-02$ \\
\hline Fa425 & $9.20 E+04$ & $1.0593 E-02$ \\
\hline Ma425 & $9.20 E+04$ & $8.0379 E-01$ \\
\hline Fi425 & $9.20 E+04$ & $1.0271 E-02$ \\
\hline Mi425 & $9.20 E+04$ & $7.7399 E-01$ \\
\hline Fi425 & $9.20 E+04$ & $1.0681 E-02$ \\
\hline Mi425 & $9.20 E+04$ & $4.6074 E-01$ \\
\hline Fk425 & $9.20 E+04$ & $1.0755 E-02$ \\
\hline Mk425 & $9.20 E+04$ & $5.9422 E-01$ \\
\hline FI425 & $9.20 E+04$ & $1.1531 E-02$ \\
\hline MI425 & $9.20 E+04$ & $8.3896 E-01$ \\
\hline Fm425 & $9.20 E+04$ & $1.2944 E-02$ \\
\hline Mm425 & $9.20 E+04$ & $6.8779 E-01$ \\
\hline BT425 & $9.20 E+04$ & $9.9000 E-01$ \\
\hline
\end{tabular}

Table 22. Pressure and liquid saturation profiles obtained using the modified version of the EOS9 module after 100 timesteps (ISOT=-7).

\begin{tabular}{|l|c|c|}
\hline Eleme & Pressure & Liq. Saturation \\
\hline & Pa & \\
\hline TP425 & $9.20 E+04$ & $1.0000 E-02$ \\
\hline Fa425 & $9.20 E+04$ & $1.0593 E-02$ \\
\hline Ma425 & $9.20 E+04$ & $8.0379 E-01$ \\
\hline FI425 & $9.20 E+04$ & $1.0271 E-02$ \\
\hline$M \mid 425$ & $9.20 E+04$ & $7.7399 E-01$ \\
\hline F/425 & $9.20 E+04$ & $1.0681 E-02$ \\
\hline MI425 & $9.20 E+04$ & $4.6074 E-01$ \\
\hline FK425 & $9.20 E+04$ & $1.0755 E-02$ \\
\hline MK425 & $9.20 E+04$ & $5.9422 E-01$ \\
\hline Fl425 & $9.20 E+04$ & $1.1531 E-02$ \\
\hline MI425 & $9.20 E+04$ & $8.3896 E-01$ \\
\hline Fm425 & $9.20 E+04$ & $1.2944 E-02$ \\
\hline Mm425 & $9.20 E+04$ & $6.8779 E-01$ \\
\hline BT425 & $9.20 E+04$ & $9.9000 E-01$ \\
\hline
\end{tabular}

Table 23. Pressure and liquid saturation profiles obtained using the qualified version of the EOS9 module after 100 timesteps (ISOT=-7) 


\begin{tabular}{|c|c|c|}
\hline Eleme & Eleme & Llquid flow \\
\hline & & $\mathrm{kg} / \mathrm{s}$ \\
\hline Fb425 & Fa425 & $0.71370 E-08$ \\
\hline Mb425 & Ma425 & $0.99849 E-08$ \\
\hline F1425 & Fh425 & $0.35468 E-14$ \\
\hline Mi425 & Mh425 & $0.44574 E-06$ \\
\hline$F / 425$ & Fi425 & 10.57607E-09 \\
\hline MI425 & Mi425 & $0.45468 \mathrm{E}-06$ \\
\hline Fk425 & Fj425 & $0.13437 E-07$ \\
\hline Mk425 & M/425 & $0.72119 E-06$ \\
\hline F/425 & Mi425 & $-0.89543 E-12$ \\
\hline$F \longdiv { 4 2 5 }$ & Mi425 & $-0.66768 \mathrm{E}-19$ \\
\hline Fk425 & Mk425 & $-0.40516 E-19$ \\
\hline F1425 & $M \mid 425$ & $-0.10202 E-08$ \\
\hline Fm425 & Mm425 & $-0.29865 E-07$ \\
\hline
\end{tabular}

Table 24. Liquid flow rate in $\mathrm{kg} / \mathrm{s}$ obtained using the modified version of the EOS9 module after 100 timesteps (ISOT=-7).

\begin{tabular}{|c|c|c|}
\hline Eleme & Eleme & Llquid flow rate \\
\hline & & $\mathrm{kg} / \mathrm{6}$ \\
\hline Fb425 & $F_{a 425}$ & $0.71370 E-08$ \\
\hline $\mathrm{Mb} 425$ & Ma425 & $0.99849 E-08$ \\
\hline F1425 & Fh425 & $0.35468 E-14$ \\
\hline Mi425 & Mh425 & $0.44574 E-06$ \\
\hline F/425 & Fi425 & $0.57607 E-09$ \\
\hline M/425 & MI425 & $0.45468 \mathrm{E}-06$ \\
\hline Fk425 & $F / 425$ & $0.13437 E-07$ \\
\hline Mk425 & $M \mid 425$ & $0.72119 \mathrm{E}-06$ \\
\hline F1425 & Mi425 & $-0.88543 E-12$ \\
\hline FI425 & Mi425 & $-0.66788 E-19$ \\
\hline Fk425 & Mk425 & $-0.40518 E-19$ \\
\hline F1425 & M/425 & $-0.10202 E-08$ \\
\hline Fm425 & Mm425 & $-0.29865 E-07$ \\
\hline
\end{tabular}

Table 25. Liquild flow rate $\mathrm{in} \mathrm{kg} / \mathrm{s}$ obtained using the qualified version of the EOS9 module after 100 timesteps (ISOT $=-7$ ). 


\subsubsection{Sample problem 7: ISOT $=-8$}

For ISOT $=-8$, the reduction factor is the product of the normalized mass flux through fracture as calculated for ISOT=-7 times upstream liquid saturation of fracture and matrix blocks. The results for the modified version of the code and the earlier version are presented in Tables 26 to 29.

\begin{tabular}{|c|c|c|}
\hline Eleme & Pressure & Llq. Saturation \\
\hline & $\mathrm{Pa}$ & \\
\hline TP425 & $9.20 E+04$ & 1.0000 E-02 \\
\hline Fa425 & $9.20 E+04$ & $1.0593 \mathrm{E}-02$ \\
\hline Ma425 & $9.20 E+04$ & $8.0379 E-01$ \\
\hline Fi425 & 9.20E+04 & $1.0271 E-02$ \\
\hline Mi425 & 9.20E+04 & $7.7399 \mathrm{E}-01$ \\
\hline$F / 425$ & $9.20 E+04$ & $1.0681 E-02$ \\
\hline Mi425 & $9.20 E+04$ & $4.6074 E-01$ \\
\hline Fk425 & $9.20 E+04$ & $1.0755 \mathrm{E}-02$ \\
\hline Mk425 & 9.20E+04 & 5.9422E-01 \\
\hline FI425 & $9.20 E+04$ & $1.1531 \mathrm{E}-02$ \\
\hline M1425 & $9.20 E+04$ & $8.3896 E-01$ \\
\hline Fm425 & 9.20E+04 & 1.2944E-02 \\
\hline Mm425 & $9.20 E+04$ & 6.8779E-01 \\
\hline BT425 & $9.20 E+04$ & 9.9000 E-01 \\
\hline
\end{tabular}

Table 26. Pressure and liquid saturation profiles obtained using the modified version of the EOS9 module after 100 timesteps (ISOT=-8).

\begin{tabular}{|l|c|r|}
\hline Eleme & Pressure & LIq. Saturatlon \\
\hline & Pa & \\
\hline TP425 & $9.20 E+04$ & $1.0000 E-02$ \\
\hline Fa425 & $9.20 E+04$ & $1.0593 E-02$ \\
\hline Ma425 & $9.20 E+04$ & $8.0379 E-01$ \\
\hline Fi425 & $9.20 E+04$ & $1.0271 E-02$ \\
\hline$M \mid 425$ & $9.20 E+04$ & $7.7399 E-01$ \\
\hline FI425 & $9.20 E+04$ & $1.0681 E-02$ \\
\hline$M \mid 425$ & $9.20 E+04$ & $4.6074 E-01$ \\
\hline Fk425 & $9.20 E+04$ & $1.0755 E-02$ \\
\hline Mk425 & $9.20 E+04$ & $5.9422 E-01$ \\
\hline Fl425 & $9.20 E+04$ & $1.1531 E-02$ \\
\hline$M \mid 425$ & $9.20 E+04$ & $8.3896 E-01$ \\
\hline Fm425 & $9.20 E+04$ & $1.2944 E-02$ \\
\hline Mm425 & $9.20 E+04$ & $6.8779 E-01$ \\
\hline BT425 & $9.20 E+04$ & $9.9000 E-01$ \\
\hline
\end{tabular}

Table 27. Pressure and liquid saturation profiles obtained using the qualified version of the EOS9 module after 100 timesteps (ISOT=-8). 


\begin{tabular}{|c|c|c|}
\hline Eleme & Eleme & Llauld flow rate \\
\hline & & $\mathrm{kg} / \mathrm{s}$ \\
\hline Fb425 & $F_{a 425}$ & $0.71370 E-08$ \\
\hline Mb425 & Ma425 & $0.99849 \mathrm{E}-08$ \\
\hline$F 1425$ & Fh425 & $0.35468 E-14$ \\
\hline M1425 & Mh425 & $0.44574 E-06$ \\
\hline$F / 425$ & Fi425 & $0.57607 E-09$ \\
\hline M) 425 & Mi425 & $0.45469 \mathrm{E}-06$ \\
\hline Fk425 & Fi425 & $0.13437 E-07$ \\
\hline Mk425 & M/425 & $0.72119 E-06$ \\
\hline F1425 & Fk425 & $0.36761 \mathrm{E}-07$ \\
\hline$M / 425$ & Mk425 & $0.13345 E .05$ \\
\hline Fm425 & $F / 425$ & $0.63386 E-07$ \\
\hline Mm425 & M1425 & $0.14906 E-05$ \\
\hline Fi425 & M1425 & $-0.89543 E-12$ \\
\hline F) 425 & M/425 & $-0.71318 E-21$ \\
\hline Fk425 & IMk425 & |-4.35740E-22 \\
\hline F/425 & MI425 & -1.02020E-09 \\
\hline$F m 425$ & Mm425 & $-2.98650 E-08$ \\
\hline Fn425 & Mn425 & $-5.28350 E-08$ \\
\hline
\end{tabular}

Table 28. Liquid flow rate in $\mathrm{kg} / \mathrm{s}$ obtained using the modified version of the EOS9 module after 100 timesteps (ISOT=-8).

\begin{tabular}{|c|c|c|}
\hline Eleme & Eleme & Llquid flow rate \\
\hline & & $\mathrm{kg} / \mathrm{s}$ \\
\hline Fb425 & Fa425 & $0.71370 E-08$ \\
\hline Mb425 & Ma425 & $0.99849 E-08$ \\
\hline F1425 & Fh425 & $0.35468 E-14$ \\
\hline M1425 & Mh425 & $0.44574 E-06$ \\
\hline$F \longdiv { 4 2 5 }$ & $F \mid 425$ & 0.57607 E-09 \\
\hline M) 425 & M1425 & $0.45469 E-06$ \\
\hline Fk425 & $F / 425$ & 0.13437 E-07 \\
\hline Mk425 & M/425 & $0.72119 E-06$ \\
\hline F1425 & Fk425 & 0.36761 E.07 \\
\hline$M 1425$ & Mk425 & $0.13345 E-05$ \\
\hline Fm425 & F1425 & $0.63386 E-07$ \\
\hline $\operatorname{Mm425}$ & MI425 & $0.14906 E-05$ \\
\hline Fi425 & $M / 425$ & $-0.89543 E-12$ \\
\hline FJ425 & $M / 425$ & $-7.1342 E-22$ \\
\hline Fk425 & Mk425 & $-4.3572 E-22$ \\
\hline F1425 & MI425 & $-1.02020 E-00$ \\
\hline Fm425 & Mm425 & $-2.98650 E-08$ \\
\hline Fn425 & Mn425 & $-5.28350 \mathrm{E}-08$ \\
\hline
\end{tabular}

Table 29. Liquid flow rate in $\mathrm{kg} / \mathrm{s}$ obtained using the qualified version of the EOS9 module after 100 timesteps (ISOT $=-8$ ). 


\subsubsection{Sample problem 8: ISOT $=-9$}

For ISOT=-9; reduction factor is a constant number (Altman et al., 1996). The constant factor is specified as $\operatorname{RP}(6)$ for each rock type in the input file and is in general obtained as an inversion parameter from ITOUGH2 (Bandurraga and Bodvarsson, 1997) based on the calibration of the 1-d model for water saturation, water potential and temperature data measured in the field.

The results are presented in Tables 30 to 33.

\begin{tabular}{|l|c|c|}
\hline Eleme & Pressure & Llq. Saturation \\
\hline & Pa & \\
\hline TP425 & $9.20 E+04$ & $1.0000 E-02$ \\
\hline Fa425 & $9.20 E+04$ & $1.0593 E-02$ \\
\hline Ma425 & $9.20 E+04$ & $8.0379 E-01$ \\
\hline Fi425 & $9.20 E+04$ & $1.0271 E-02$ \\
\hline Mi425 & $9.20 E+04 \mid$ & $7.7399 E-01$ \\
\hline Fj425 & $9.20 E+04$ & $1.0681 E-02$ \\
\hline Mi425 & $9.20 E+04$ & $4.6075 E-01$ \\
\hline FK425 & $9.20 E+04$ & $1.0755 E-02$ \\
\hline MK425 & $9.20 E+04$ & $5.0422 E-01$ \\
\hline BT425 & $9.20 E+04$ & $9.0000 E-01$ \\
\hline
\end{tabular}

Table 30. Pressure and liquid saturation profiles obtained using the modified version of the EOS9 module after 100 timesteps (ISOT=-9).

\begin{tabular}{|c|c|c|}
\hline Eleme & Pressure & Llq. Saturation \\
\hline & $\mathrm{Pa}$ & \\
\hline TP425 & $9.20 E+04$ & 1.0000E-02 \\
\hline $\mathrm{Fa} 425$ & $9.20 E+04$ & $1.0593 \mathrm{E}-02$ \\
\hline Ma425 & $9.20 E+04$ & $8.0379 \mathrm{E}-01$ \\
\hline FI425 & $9.20 E+04$ & -02 \\
\hline MI425 & $9.20 E+04$ & $E-01$ \\
\hline F/425 & $9.20 E+04$ & $1 E-02$ \\
\hline M/425 & $9.20 E+04$ & $4.6075 E-01$ \\
\hline Fk425 & $9.20 E+04$ & $1.0755 E-02$ \\
\hline Mk425 & $9.20 E+04$ & 5.9422E-01 \\
\hline BT425 & $9.20 E+04$ & $9.9000 E-01$ \\
\hline
\end{tabular}

Table 31. Pressure and liquid saturation profiles obtained using the qualified version of the EOS9 module after 100 timesteps (ISOT=-9). 


\begin{tabular}{|c|c|c|}
\hline Eleme & Eleme & Llquid flow rate \\
\hline & & kg/s \\
\hline Fb425 & Fa425 & $0.71370 E-08$ \\
\hline Mb425 & Ma425 & $0.99850 E-08$ \\
\hline Mi425 & Fh425 & $0.35468 E-14$ \\
\hline Fi425 & Fi425 & $0.44574 E-06$ \\
\hline MI425 & Mi425 & $0.57607 E-09$ \\
\hline Fk425 & Fi425 & $0.15469 E-06$ \\
\hline Mk425 & Mi425 & $0.72119 E-06$ \\
\hline FI425 & Fk425 & $0.36761 E-07$ \\
\hline MI425 & Mk425 & $0.13345 E-05$ \\
\hline Fm425 & FI425 & $0.63386 E-07$ \\
\hline Mm425 & MI425 & $0.14906 E-05$ \\
\hline Fi425 & Mi425 & $-0.89543 E-12$ \\
\hline Fj425 & Mj425 & $-0.11039 E-12$ \\
\hline Fk425 & Mk425 & $-2.52920 E-14$ \\
\hline FI425 & MI425 & $-1.02020 E-09$ \\
\hline Fm425 & Mm425 & $-2.98650 E-08$ \\
\hline
\end{tabular}

Table 32. Liquid flow rate in $\mathrm{kg} / \mathrm{s}$ obtained using the modified version of the EOS9 module after 100 timesteps (ISOT=-9).

\begin{tabular}{|c|c|c|}
\hline Eleme & Eleme & Liquid flow rate \\
\hline & & kg/s \\
\hline Fb425 & Fa425 & $0.71370 E-08$ \\
\hline Mb425 & Ma425 & $0.99850 E-08$ \\
\hline FI425 & Fh425 & $0.35468 E-14$ \\
\hline Mi425 & Mh425 & $0.44574 E-06$ \\
\hline Fl425 & FI425 & $0.57607 E-09$ \\
\hline Mj425 & Mi425 & $0.45469 E-06$ \\
\hline Fk425 & Fi425 & $0.13436 E-07$ \\
\hline Mk425 & Mj425 & $0.72119 E-06$ \\
\hline FI425 & Fk425 & $0.36761 E-07$ \\
\hline MI425 & Mk425 & $0.13345 E-05$ \\
\hline Fm425 & FI425 & $0.63386 E-07$ \\
\hline Mm425 & MI425 & $0.14906 E-05$ \\
\hline Fi425 & Mi425 & $-0.89543 E-12$ \\
\hline Fj425 & Mj425 & $-0.11043 E-12$ \\
\hline Fk425 & Mk425 & $-2.52970 E-14$ \\
\hline Fl425 & MI425 & $-1.02020 E-09$ \\
\hline Fm425 & Mm425 & $-2.98650 E-08$ \\
\hline
\end{tabular}

Table 33. Liquid flow rate in $\mathrm{kg} / \mathrm{s}$ obtained using the qualified version of the EOS9 module after 100 time steps (ISOT=-9). 


\subsection{Sample problem 9:}

\section{Modified weighting scheme for vitric/zeolitic matrix interface}

A one-dimensional column as described for the earlier problems is used. The special treatment of flow in the matrix for a dual-permeability formulation where a vitric layer overlies a zeolitic layer is done by setting ISOT $=-2$ for the matrix to matrix connection between the vitric and the zeolitic elements. A small section of the input file (CONNE block) is shown in Figure 8. In this case the modified weighting scheme used for flow calculations are based on downstream mobility.

For this problem, EOS9 is used to simulate the two-phase conditions. A constant influx rate is specified at the second element from the top. The output at steady-state are given below in Tables 34 and 35 showing that the saturations are very similar in the two simulations presented. The steady state mass flow rate for the various elements are given in Tables 36 and 37. The results between the modified and the previous qualified versions are similar, indicating a consistent performance of the codes.

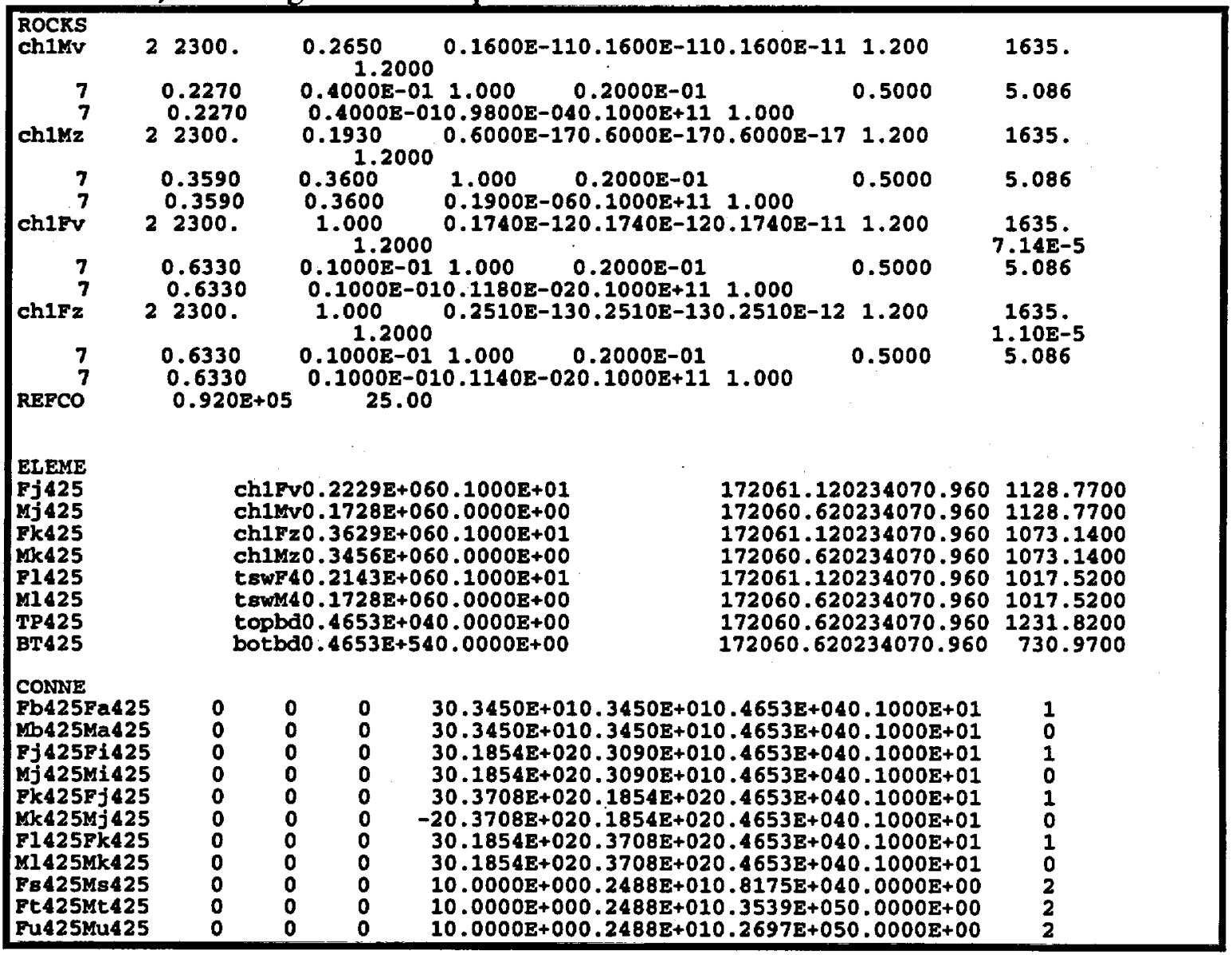

Figure 8. Selected input file for sample problem 9. 


\begin{tabular}{|l|c|c|}
\hline Eleme & Pressure & LIq. Saturation \\
\hline & $P a$ & \\
\hline TP425 & $9.20 E+04$ & $1.0000 E-02$ \\
\hline Fa425 & $9.20 E+04$ & $1.0528 E-02$ \\
\hline Ma425 & $9.20 E+04$ & $6.3472 E-01$ \\
\hline Fb425 & $9.20 E+04$ & $1.0540 E-02$ \\
\hline Mb425 & $9.20 E+04$ & $6.3661 E-01$ \\
\hline Fk425 & $9.20 E+04$ & $1.0035 E-02$ \\
\hline Mk425 & $9.20 E+04$ & $9.0926 E-01$ \\
\hline Fu425 & $9.20 E+04$ & $1.0066 E-02$ \\
\hline Mu425 & $9.20 E+04$ & $8.3499 E-01$ \\
\hline BT425 $\mid 9.20 E+04$ & $9.9000 E-01$ \\
\hline
\end{tabular}

Table 34. Steady state pressure and liquid saturation profiles obtained using the modified version of the EOS9 module for special treatment of the vitric/zeolitic interface.

\begin{tabular}{|l|c|c|}
\hline Eleme & Pressure & Liq. Saturation \\
\hline & Pa & \\
\hline TP425 & $9.20 E+04$ & $1.0000 E-02$ \\
\hline Fa425 & $1.09 E+06$ & $1.0528 E-02$ \\
\hline Ma425 & $9.20 E+04$ & $6.3431 E-01$ \\
\hline Fb425 & $9.20 E+04$ & $1.0540 E-02$ \\
\hline Mb425 & $9.20 E+04 \mid$ & $6.3619 E-01$ \\
\hline Fk425 & $9.20 E+04 \mid$ & $1.0042 E-02$ \\
\hline Mk425 & $9.20 E+04 \mid$ & $9.0923 E-01$ \\
\hline Fu425 & $9.20 E+04$ & $1.0065 E-02$ \\
\hline Mu425 & $9.20 E+04$ & $8.3499 E-01$ \\
\hline BT425 & $9.20 E+04 \mid$ & $9.9000 E-01$ \\
\hline
\end{tabular}

Table 35. Steady state pressure and liquid saturation profiles obtained using the qualified version of the EOS9 module for special treatment of the vitric/zeolitic interface.

\begin{tabular}{|l|l|l|}
\hline Eleme & Eleme & Llquid flow rate \\
\hline & $\mid$ & $\mathrm{kg} / \mathrm{s}$ \\
\hline Fb425 & Fa425 & $0.49071 E-08$ \\
\hline Mb425 & Ma425 & $0.58686 E-11$ \\
\hline Mi425 & Mh425 & $0.49130 E-08$ \\
\hline Mi425 & Mi425 & $0.49130 E-08$ \\
\hline Mk425 & Mi425 & $0.49130 E-08$ \\
\hline Mi425 & Mk425 & $0.49130 E-08$ \\
\hline BT425 & Mu425 & $0.49166 E-08$ \\
\hline
\end{tabular}

Table 36. Steady-state liquid flow rate in $\mathrm{kg} / \mathrm{s}$ obtained using the modified version of the EOS9 module. 


\begin{tabular}{|l|l|l|}
\hline Eleme & Eleme & Llquid flow rate \\
\hline & & $\mathrm{kg} / \mathrm{s}$ \\
\hline Fb425 & Fa425 & $0.49071 E-08$ \\
\hline Mb425 & Ma425 & $0.58862 E-11$ \\
\hline Mi425 & Mh425 & $0.49129 E-08$ \\
\hline Mi425 & Mi425 & $0.49130 E-08$ \\
\hline Mk425 & Mi425 & $0.49130 E-08$ \\
\hline MI425 & Mk425 & $0.49130 E-08$ \\
\hline BT425 & Mu425 & $0.49130 E-08$ \\
\hline
\end{tabular}

Table 37. Steady-state liquid flow rate in $\mathrm{kg} / \mathrm{s}$ obtained using the qualified version of the EOS9 module.

\subsection{Sample problem 10: \\ Post processing of TOUGH2 output}

An additional subroutine for calculating the nodal velocities and fluxes has been developed. A sample problem was developed to check the output file, tough 2.tec, for the values of velocities and fluxes at different nodes. A uniform two-dimensional mesh $(10 \mathrm{~m}$ $\times 10 \mathrm{~m} \times 1 \mathrm{~m}$ ) was generated using the MESHMAKER capabilities of the TOUGH2 code. The model problem consists of a two-dimensional flow domain with a constant isotropic permeability $\left(\mathrm{k}=0.8904 \mathrm{E}-12 \mathrm{~m}^{2}\right)$ and a constant pressure difference of $1 \mathrm{E}+05 \mathrm{~Pa}$ applied across the two edges. The calculated velocity for this simple system is $0.8712 \mathrm{E}-06 \mathrm{~m} / \mathrm{s}$ along the direction of the pressure gradient and zero across it and the results obtained from the simulations also gives the same value (Tables 38 and 39).

The input file for this problem is given in Figure 9.

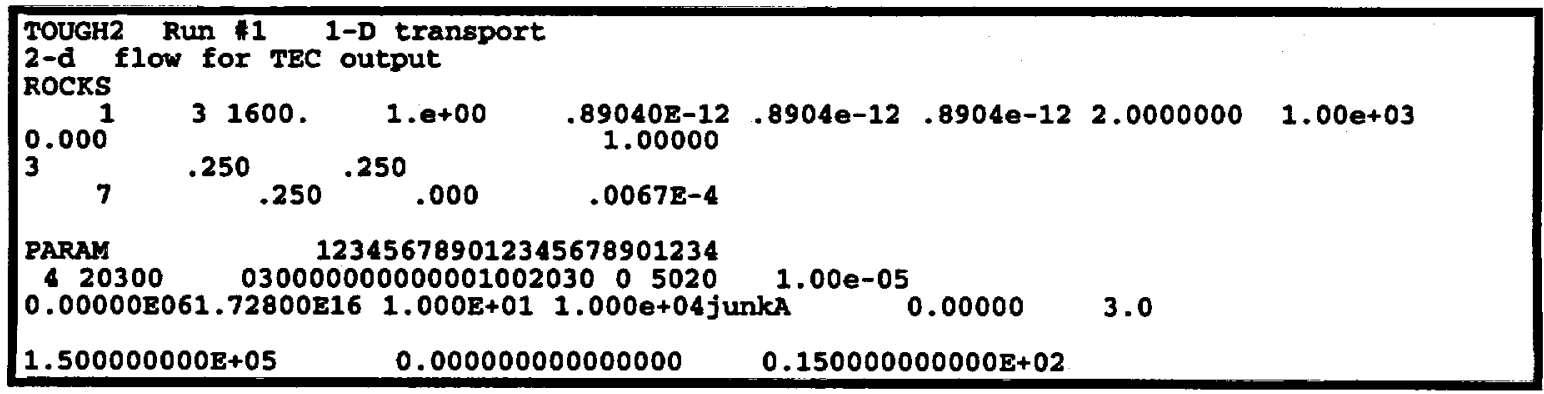

Figure 9. Selected input file for sample problem 10. 


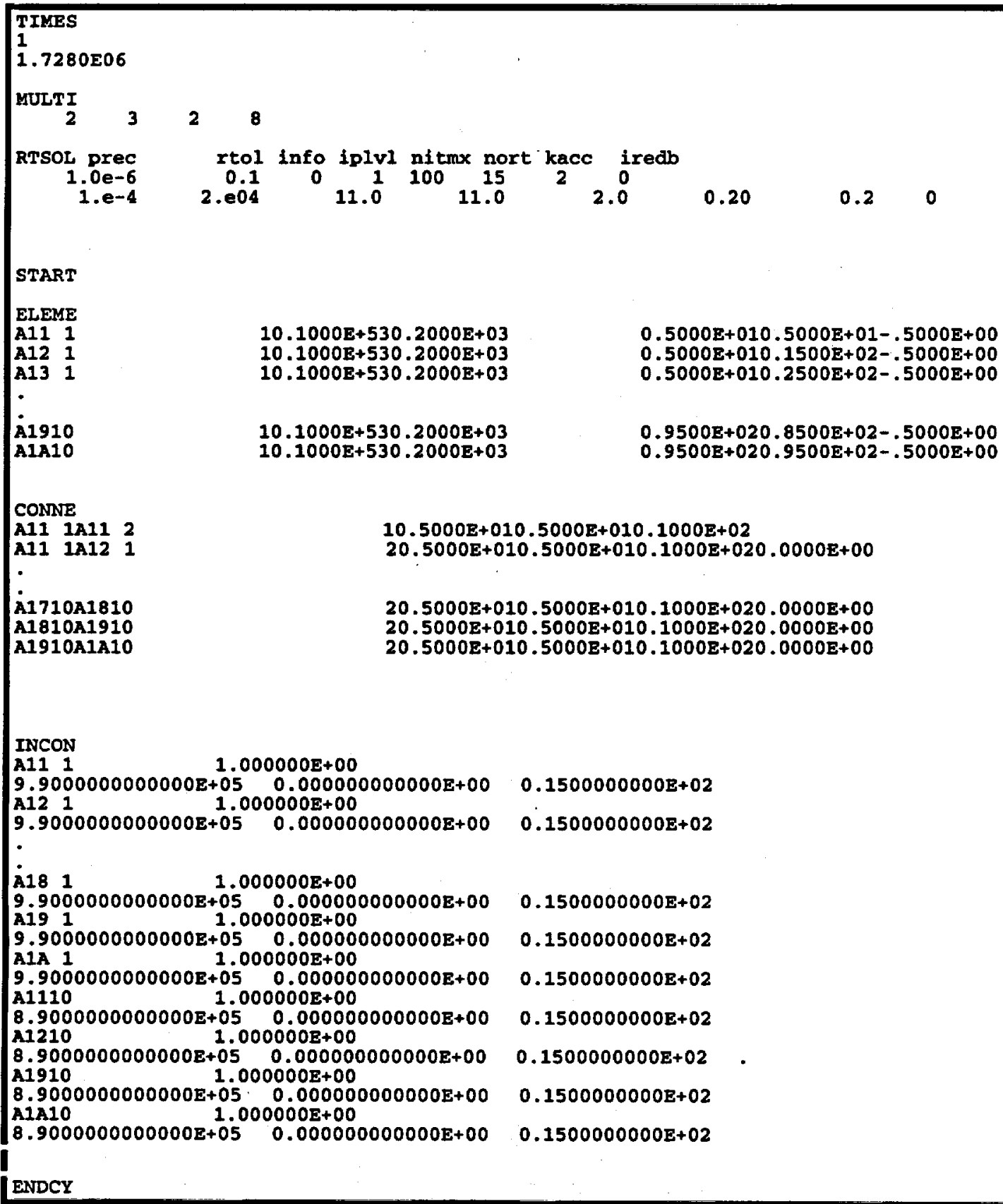

$10.1000 \mathrm{E}+530.2000 \mathrm{E}+03$

$10.1000 \mathrm{E}+530.2000 \mathrm{E}+03$

$10.1000 \mathrm{E}+530.2000 \mathrm{E}+03$

$10.1000 \mathrm{E}+530.2000 \mathrm{E}+03$

$10.1000 \mathrm{E}+530.2000 \mathrm{E}+03$

\begin{abstract}
$0.5000 \mathrm{E}+010.1500 \mathrm{E}+02-.5000 \mathrm{E}+00$ $0.5000 \mathrm{E}+010.2500 \mathrm{E}+02-.5000 \mathrm{E}+00$

$0.9500 \mathrm{E}+020.8500 \mathrm{E}+02-.5000 \mathrm{E}+00$ $0.9500 \mathrm{E}+020.9500 \mathrm{E}+02-.5000 \mathrm{E}+00$
\end{abstract}

$0.5000 \mathrm{E}+010.5000 \mathrm{E}+01-.5000 \mathrm{E}+00$

CONNE

A11 1 A11 2

$10.5000 \mathrm{E}+010.5000 \mathrm{E}+010.1000 \mathrm{E}+02$

A11 1 A12 1

$20.5000 \mathrm{E}+010.5000 \mathrm{E}+010.1000 \mathrm{E}+020.0000 \mathrm{E}+00$

A1710A1810

A1810A1910

$20.5000 \mathrm{E}+010.5000 \mathrm{E}+010.1000 \mathrm{E}+020.0000 \mathrm{E}+00$ $20.5000 \mathrm{E}+010.5000 \mathrm{E}+010.1000 \mathrm{E}+020.0000 \mathrm{E}+00$

A1910A1A10

$20.5000 \mathrm{E}+010.5000 \mathrm{E}+010.1000 \mathrm{E}+020.0000 \mathrm{E}+00$

INCON

A11 1 1.000000E+00

$9.9000000000000 \mathrm{E}+05 \quad 0.000000000000 \mathrm{E}+00 \quad 0.1500000000 \mathrm{E}+02$

A12 $1 \quad 1.000000 \mathrm{E}+00$

$9.9000000000000 \mathrm{E}+05 \quad 0.000000000000 \mathrm{E}+00 \quad 0.1500000000 \mathrm{E}+02$

:

A18 $1 \quad 1.000000 \mathrm{E}+00$

$9.9000000000000 \mathrm{E}+05 \quad 0.000000000000 \mathrm{E}+00 \quad 0.1500000000 \mathrm{E}+02$

Aig 1 1.000000E+00

$\begin{array}{lll}9.9000000000000 \mathrm{E}+05 & 0.000000000000 \mathrm{E}+00 & 0.1500000000 \mathrm{E}+02\end{array}$

$\begin{array}{ll}\text { A1A } 1 & 1.000000 \mathrm{E}+00\end{array}$

$9.9000000000000 \mathrm{E}+05 \quad 0.000000000000 \mathrm{E}+00 \quad 0.1500000000 \mathrm{E}+02$

Ai110 $1.000000 \mathrm{E}+00$

$8.9000000000000 \mathrm{E}+05 \quad 0.000000000000 \mathrm{E}+00 \quad 0.1500000000 \mathrm{E}+02$

A1210 $1.000000 \mathrm{E}+00$

$8.9000000000000 \mathrm{E}+05 \quad 0.000000000000 \mathrm{E}+00 \quad 0.1500000000 \mathrm{E}+02$.

A1910 $1.000000 \mathrm{E}+00$

$8.9000000000000 \mathrm{E}+05, \quad 0.000000000000 \mathrm{E}+00 \quad 0.1500000000 \mathrm{E}+02$

A1A10 $1.000000 \mathrm{E}+00$

$\begin{array}{lll}8.9000000000000 \mathrm{E}+05 & 0.000000000000 \mathrm{E}+00 & 0.1500000000 \mathrm{E}+02\end{array}$

ENDCY

Figure 9. Selected input file for sample problem 10 (contd.). 


\begin{tabular}{|c|c|c|c|}
\hline Eleme & Eleme & Llquid velocity & Liquid Mass flux \\
\hline & & $\mathrm{m} / \mathrm{s}$ & $\mathrm{kg} / \mathrm{s}$ \\
\hline A11 1 & A112 & $-8.7121 E-07$ & $-8.7088 E-03$ \\
\hline A12 1 & A122 & $-8.7121 E-07$ & $-8.7088 E-03$ \\
\hline A13 1 & A132 & $-8.7121 E-07$ & $-8.7088 E-03$ \\
\hline A14 1 & A14 2 & $-8.7121 E-07 \mid$ & $-8.7088 E-03$ \\
\hline A15 1 & A15 2 & $-8.7121 E-07 \mid$ & $-8.7088 E-03$ \\
\hline A16 1 & A16 2 & $-8.7121 E-07$ & $-8.7088 E-03$ \\
\hline
\end{tabular}

Table 38. Flow velocity $(\mathrm{m} / \mathrm{s})$ and mass flux $(\mathrm{kg} / \mathrm{s})$ between two elements for some selected interfaces as obtained from the output of EOS3 module.

By selecting MOP(23)=2, TOUGH2 proceeds with the postprocessing of the state variables to calculate the velocity field in a format which can be used for plotting. The output is written to file, tough2.tec, and an abstracted version of the output file showing the liquid velocity and the mass flux in the $\mathrm{x}$ direction is given in Table 39.

\begin{tabular}{|c|c|c|c|}
\hline $\mathrm{X}$ & $\mathrm{Y}$ & $\mathrm{VLX}$ & $\mathrm{FMx}$ \\
\hline $\mathrm{m}$ & $\mathrm{m}$ & $\mathrm{m} / \mathrm{s}$ & $\mathrm{kg} / \mathrm{s} / \mathrm{m}^{2}$ \\
\hline 5 & 5 & $8.7121 \mathrm{E}-07$ & 0.00087088 \\
\hline 5 & 15 & $8.7121 \mathrm{E}-07$ & 0.00087088 \\
\hline 5 & 25 & $8.7121 \mathrm{E}-07$ & 0.00087088 \\
\hline 5 & 35 & $8.7121 \mathrm{E}-07$ & 0.00087088 \\
\hline 5 & 45 & $8.7121 \mathrm{E}-07$ & 0.00087088 \\
\hline 5 & 55 & $8.7121 \mathrm{E}-07$ & 0.00087088 \\
\hline 5 & 65 & $8.7121 \mathrm{E}-07$ & 0.00087088 \\
\hline 5 & 75 & $8.7121 \mathrm{E}-07$ & 0.00087088 \\
\hline 5 & 85 & $8.7121 \mathrm{E}-07$ & 0.00087088 \\
\hline 5 & 85 & $8.7121 \mathrm{E}-07$ & 0.00087088 \\
\hline
\end{tabular}

Table 39. Liquid velocity in the $x$ direction abstracted from the tough2.tec file for the two-dimensional flow problem. 


\subsection{Sample problem 11: \\ Transport module with dual permeability formulation (T2R3D)}

The previously qualified version of T2R3D was developed for both the ECM and dual-permeability approaches for handling transport in fractured media (Wu et al., 1996). In the previous sections we have outlined several interface reduction schemes as the addition to the dual-permeability formulation for flow and transport. These modifications are identical to those discussed above for the EOS9 or EOS3 modules. In this section the T2R3D module is updated to incorporate the additional feature of transport in a dualpermeability media. The sample problem is designed for running the T2R3D code for the transport of a non-sorbing tracer. A one-dimensional grid with the dual permeability formulation is chosen. Transport of an ideal tracer under two-phase and non-isothermal conditions is simulated. Both inlet and outlet boundary conditions are specified to be at constant pressure, liquid saturation, radionuclide mass fraction and temperature by specifying a huge volume. Transport of the ideal tracer occurs through advection and molecular diffusion. The molecular diffusion coefficient is $1.0 \mathrm{E}-10 \mathrm{~m} / \mathrm{s}$ for the matrix and $1.0 \mathrm{E}-13 \mathrm{~m}^{2} / \mathrm{s}$ in the fractures.

The T2R3D module was setup for the one-dimensional problem to validate the revised version of the module. Figure 10 shows the input file for this problem. The mass fraction distribution of the tracer at each element at steady state is shown for the two versions of the code and they are identical (Tables 40 and 41). The flux rate calculations also give similar results (Table 42 and 43).

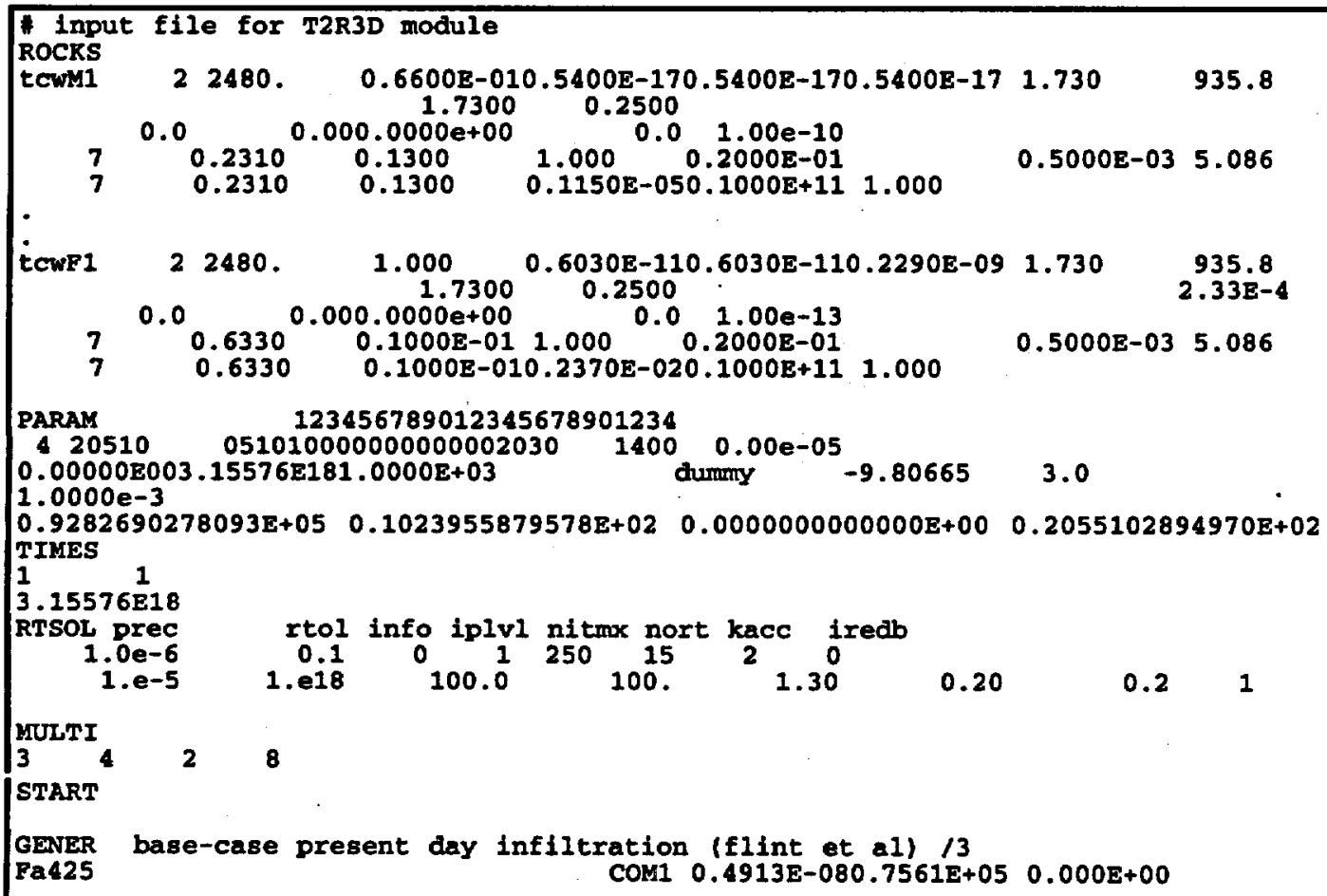

Figure 10. Input file for sample problem 11 - T2R3D for dual-permeability. 


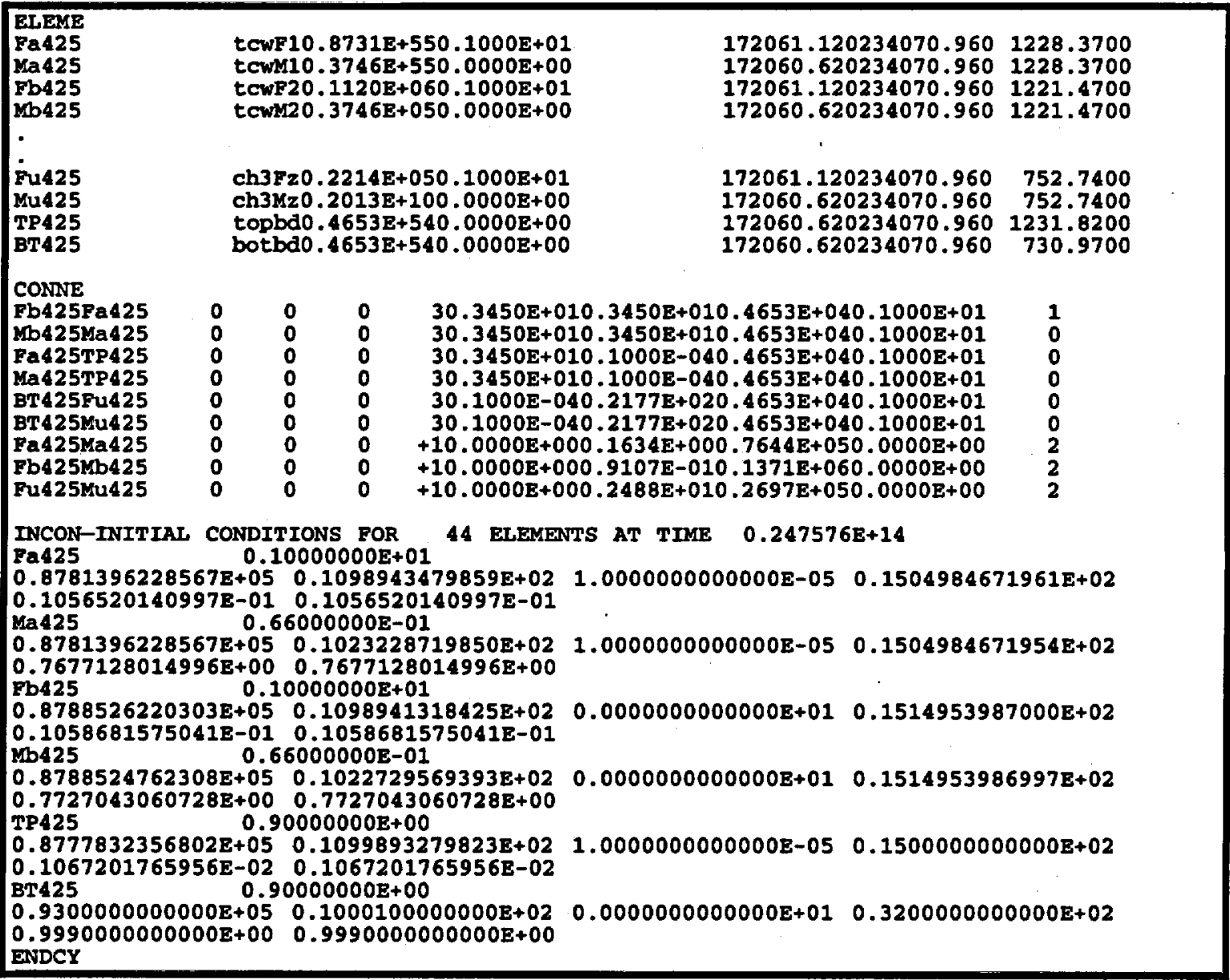

Figure 10. Input file for sample problem 11 - T2R3D for dual-permeability (contd.).

\begin{tabular}{|l|r|}
\hline Eleme & Tracer M.F. \\
\hline Fa425 & $1.00 E-05$ \\
\hline Ma425 & $1.00 E-05$ \\
\hline Fb425 & $1.00 E-05$ \\
\hline Mb425 & $1.00 E-05$ \\
\hline Fu425 & $4.70 E-48$ \\
\hline Mu425 & $1.67 E-07$ \\
\hline TP425 & $1.00 E-05$ \\
\hline BT425 & $1.75 E-53$ \\
\hline
\end{tabular}

Table 40. Mass fraction of the tracer at steady-state conditions for the modified T2R3D module. 


\begin{tabular}{|l|r|}
\hline Eleme & Tracer M.F. \\
\hline Fa425 & $1.00 E-05$ \\
\hline Ma425 & $1.00 E-05$ \\
\hline Fb425 & $1.00 E-05$ \\
\hline Mb425 & $1.00 E-05$ \\
\hline Fu425 & $4.70 E-48$ \\
\hline Mu425 & $1.67 E-07$ \\
\hline TP425 & $1.00 E-05$ \\
\hline BT425 & $1.75 E-53$ \\
\hline
\end{tabular}

Table 41. Mass fraction of the tracer at steady-state conditions for the qualified T2R3D module.

\begin{tabular}{|l|l|l|}
\hline Eleme & Eleme & Liquld flow rate \\
\hline & & $\mathrm{kg} / \mathrm{s}$ \\
\hline Fb425 & Fa425 & $4.9296 \mathrm{E}-09$ \\
\hline Mb425 & Ma425 & $1.4474 E-07$ \\
\hline Fr425 & Fq425 & $7.0281 E-11$ \\
\hline Mr425 & Mq425 & $1.5063 E-07$ \\
\hline Fs425 & Fr425 & $1.2782 E-10$ \\
\hline Ms425 & Mr425 & $1.5064 E-07$ \\
\hline Ft425 & Fs425 & $3.1275 E-10$ \\
\hline Mt425 & Ms425 & $1.5059 E-07$ \\
\hline Fu425 & Ft425 & $6.0271 E-10$ \\
\hline Mu425 & Mt425 & $1.5059 E-07$ \\
\hline BT425 & Fu425 & $7.3533 E-10$ \\
\hline BT425 & Mu425 & $1.5059 E-07$ \\
\hline Fa425 & Ma425 & $-2.2955 E-12$ \\
\hline Fu425 & Mu425 & $-6.5005 E-13$ \\
\hline
\end{tabular}

Table 42. Liquid flow rate $(\mathrm{kg} / \mathrm{s})$ for the modified T2R3D module. 


\begin{tabular}{|l|l|l|}
\hline Eleme & Eleme & Llquld flow rate \\
\hline & & $\mathrm{kg} / \mathrm{s}$ \\
\hline Fb425 & Fa425 & $4.9296 \mathrm{E}-09$ \\
\hline Mb425 & Ma425 & $1.4474 \mathrm{E}-07$ \\
\hline Fr425 & Fq425 & $7.0281 E-11$ \\
\hline Mr425 & Mq425 & $1.5063 E-07$ \\
\hline Fs425 & Fr425 & $1.2782 E-10$ \\
\hline Ms425 & Mr425 & $1.5064 E-07$ \\
\hline Ft425 & Fs425 & $3.1275 E-10$ \\
\hline Mt425 & Ms425 & $1.5059 E-07$ \\
\hline Fu425 & Ft425 & $6.0271 E-10$ \\
\hline Mu425 & Mt425 & $1.5059 E-07$ \\
\hline BT425 & Fu425 & $7.3533 E-10$ \\
\hline BT425 & Mu425 & $1.5059 E-07$ \\
\hline Fa425 & Ma425 & $-2.2955 E-12$ \\
\hline Fu425 & Mu425 & $-6.5005 E-13$ \\
\hline
\end{tabular}

Table 43. Liquid flow rate $(\mathrm{kg} / \mathrm{s})$ for the qualified T2R3D module.

\subsection{Sample problem 12: Addition of a modified relative permeability model in the EOS1G module}

A one-dimensional flow model is here used to validate the revised EOS1G module. As noted earlier a modified form of relative permeability function for two-phase condition is used which provides for greater interference between the liquid and the air phase. The model consists of 100 elements. The boundary condition is Dirichlet-type where the bottom boundary node is held at a constant pressure of $90 \mathrm{kPa}$. The input file is given in Figure 11. The propagation of the pressure pulse through the one-dimensional system is compared between the earlier version and the revised version of the codes. In the earlier qualified version, $k_{\mathrm{rg}}=1-\mathrm{k}_{\mathrm{f}}$ whereas in the revised model an explicit form of the relative permeability to gas is obtained by using the modified form of the Brooks-Corey relation as discussed earlier.

The pressure profile after 1 day is shown below. Tables 44 through 47 compare the results between the revised version of EOS1G using the new relative permeability function and the qualified EOS1G code. The results show that the two versions give very similar results, with a maximum difference observed to be less than $0.2 \%$. The position of the pressure front is also at the same position in both the results. 


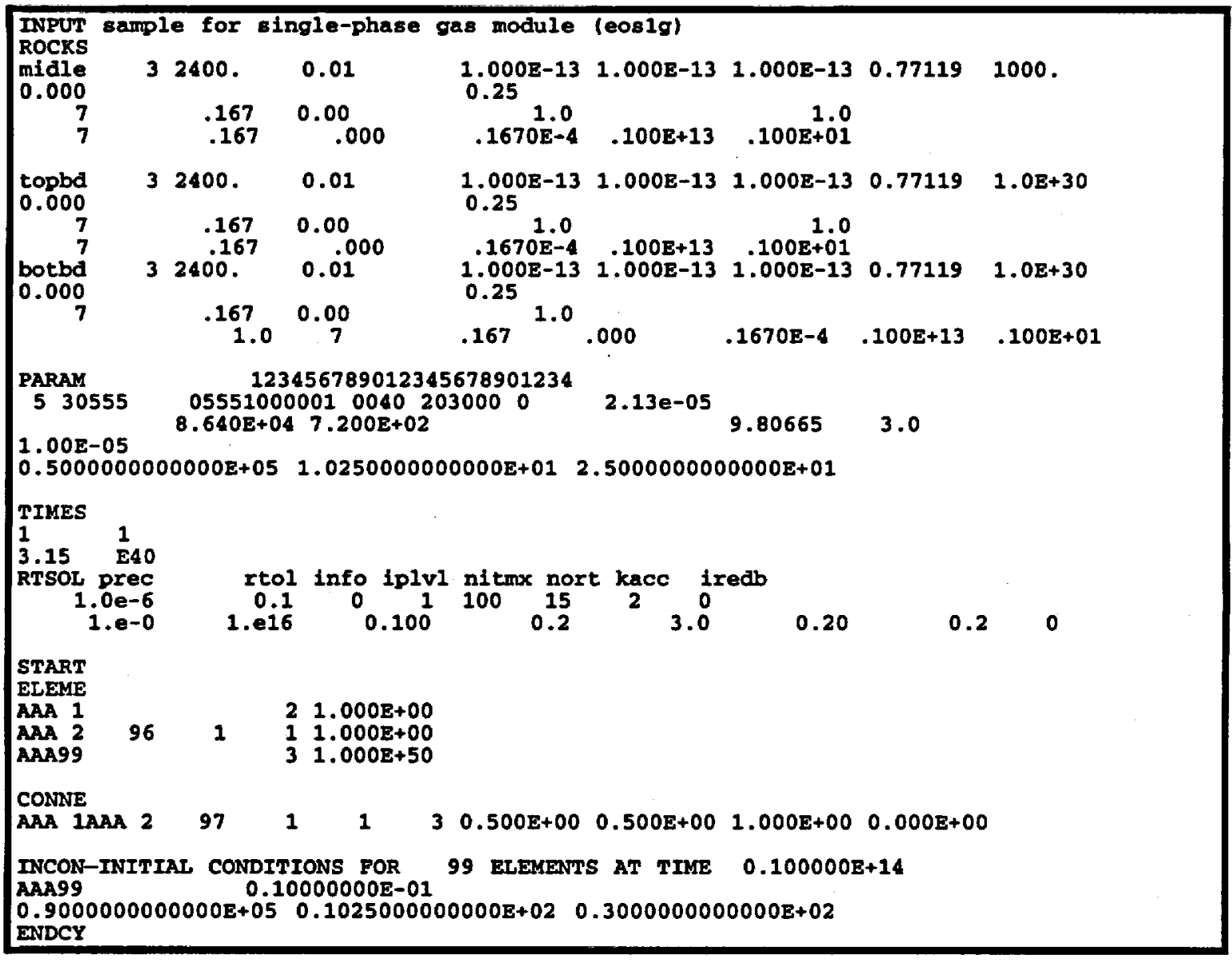

Figure 11. Input file for sample problem 12- EOS1G module.

\begin{tabular}{|l|c|}
\hline Eleme & Gas pressure \\
\hline & Pa \\
\hline AAA01 & $5.1320 E+04$ \\
\hline AAA02 & $5.1323 E+04$ \\
\hline AAA03 & $5.1330 E+04$ \\
\hline AAA04 & $5.1341 E+04$ \\
\hline AAA93 & $8.5146 E+04$ \\
\hline AAA94 & $8.5961 E+04$ \\
\hline AAA95 & $8.6773 E+04$ \\
\hline AAA96 & $8.7581 E+04$ \\
\hline AAA97 & $8.8384 E+04$ \\
\hline AAA98 & $8.9182 E+04$ \\
\hline AAA99 & $9.0000 E+04$ \\
\hline
\end{tabular}

Table 44. Gas pressure at selected nodes $(\mathrm{Pa})$ for the revised EOS1G module. 


\begin{tabular}{|l|c|}
\hline Eleme & Gas pressure \\
\hline & Pa \\
\hline AAA01 & $5.1201 E+04$ \\
\hline AAA02 & $5.1205 E+04$ \\
\hline AAA03 & $5.1212 E+04$ \\
\hline AAA04 & $5.1222 E+04$ \\
\hline AAA93 & $8.5314 E+04$ \\
\hline AAA94 & $8.6101 E+04$ \\
\hline AAA95 & $8.6885 E+04$ \\
\hline AAA96 & $8.7665 E+04$ \\
\hline AAA97 & $8.8440 E+04$ \\
\hline AAA98 & $8.9210 E+04$ \\
\hline AAA99 & $9.0000 E+04$ \\
\hline
\end{tabular}

Table 45. Gas pressure at selected nodes $(\mathrm{Pa})$ for the qualified EOS1G module.

\begin{tabular}{|l|l|l|}
\hline Eleme & Eleme Gas & Velocity \\
\hline & & $\mathrm{m} / \mathrm{s}$ \\
\hline AAA01 & AAA02 & $4.6475 \mathrm{E}-07$ \\
\hline AAA02 & AAA03 & $9.3055 \mathrm{E}-07$ \\
\hline AAA03 & AAA04 & $1.3985 \mathrm{E}-06$ \\
\hline AAA04 & AAA05 & $1.8696 \mathrm{E}-06$ \\
\hline AAA95 & AAA96 & $1.0565 \mathrm{E}-04$ \\
\hline AAA96 & AAA97 & $1.0502 \mathrm{E}-04$ \\
\hline AAA97 & AAA98 & $1.0429 \mathrm{E}-04$ \\
\hline AAA98 & AAA99 & $1.0648 \mathrm{E}-04$ \\
\hline
\end{tabular}

Table 46. Gas velocity at selected nodes $(\mathrm{m} / \mathrm{s})$ for the modified EOS1G module.

\begin{tabular}{|l|l|c|}
\hline Eleme & Eleme & Gas Velocity \\
\hline & & $\mathrm{m} / \mathrm{s}$ \\
\hline AAA01 & AAA02 & $4.6498 \mathrm{E}-07$ \\
\hline AAA02 & AAA03 & $9.3113 \mathrm{E}-07$ \\
\hline AAA03 & AAA04 & $1.3996 \mathrm{E}-06$ \\
\hline AAA04 & AAA05 & $1.8717 \mathrm{E}-06$ \\
\hline AAA95 & AAA96 & $1.0188 \mathrm{E}-04$ \\
\hline AAA96 & AAA97 & $1.0126 \mathrm{E}-04$ \\
\hline AAA97 & AAA98 & $1.0056 \mathrm{E}-04$ \\
\hline AAA98 & AAA99 & $1.0270 \mathrm{E}-04$ \\
\hline
\end{tabular}

Table 47. Gas velocity at selected nodes $(\mathrm{m} / \mathrm{s})$ for the qualified EOS1G module. 


\title{
5. Software User Documentation
}

\section{Input and Output}

\subsection{Single-Phase Gas Flow Module (EOS1G)}

Input and output files, file formats, options, default parameters, data files, commands, and execution for this module are the same as described for the TOUGH2 EOS3 module in section 5.3 of Pruess et al. (1996). The modified form of the relative permeability to the gas phase is input through record "ROCKS" in the TOUGH2 code, and the related modifications in input data are read in card ROCKS.1.2

\author{
Card ROCKS.1.2 (I5,5X,7E10.4) IRP, RP(i), i=1, 7 \\ IRP $=7$ for the modified form of relative permeability to gas \\ $R P(1)=m \quad v a n$ Genuchten parameter (Eq. 11) \\ $R P(2)=S_{\mathrm{lr}}$ residual liquid saturation (Eq. 10) \\ $\mathbf{R P}(3)=\mathbf{S}_{\max }$ maximum liquid saturation (Eq. 10)
}

\subsection{Interface area reduction scheme in module EOS9 or EOS3 or T2R3D}

For the unsaturated/saturated flow in dual-permeability media, the input data and formats are the same as those for the TOUGH2 EOS3, EOS9 and T2R3D module (Pruess, 1987, 1991; Wu et al., 1996), except the following changes in CONNE and ELEME blocks. These changes in ISOT value are made for the corresponding fracture-matrix connections only.

Card CONNE.1 (A3, 12, A3, I2, 415, 4E10.4) EL1, NE1, EL2, NE2, NSEQ, NAD1, NAD2, ISOT, D1, D2, AREAX, BETAX

ISOT is set to $-1,-3,-4,-7,-8$, or -9 for the corresponding scenarios as discussed before.

We also need a change in the following ELEME card:

Card ELEME.1 (A5, 10X, A3, A2, 2E10.4, 10x, 3F10.3) ELEM, MA1, MA2, VOLX, AHT, X, Y, Z

Here AHT is used as an identifier for fracture elements. AHT $>0$ is for fracture elements in the dual-permeability simulations. AHT $=0$ or default is used for non dualpermeability runs, and is for matrix elements for a dual-permeability grid. $\mathrm{X}, \mathrm{Y}, \mathrm{Z}$ are coordinates of the center of the element.

\subsection{Modified weighting scheme at vitric/zeolitic interface}

For the dual-permeability formulation, a special scheme only for the matrix-matrix connection is implemented when a vitric layer overlies a zeolitic layer. The following change is implemented in CONNE block for the ISOT value.

Card CONNE.1 (A3,12,A3,I2, 4I5, 4E10.4) EL1, NE1, EL2, NE2, NSEQ, NAD1, NAD2, ISOT, D1, D2, AREAX, BETAX

ISOT is set to -2 to invoke this option. 


\subsection{Output files for visualization}

Formatted outputs of fluid velocities and mass fluxes which can be used directly by commercial visualization softwares are now available in TOUGH2. This feature is enabled by using the PARAM.1 card and the following changes.

(a) Cand PARAM.1 (2I2, 3I4, 24I1, 2E10.4) NOITE, KDATA, MCYC, MSEC, MCYPR, (MOP(I), I=1, 24), DIFF0, TEXP
$\operatorname{MOP}(23)=0, \quad$ no postprocessing option.
$\operatorname{MOP}(23)=1, \quad \begin{aligned} & \text { postprocessing of primary variables like pressures, saturations, } \\ & \text { temperature, capillary pressure written to a file, tough2.tec. }\end{aligned}$
$\operatorname{MOP}(23)=2, \quad$ postprocessing of primary variables, in addition, pore velocities and mass fluxes at the nodes written to a file, tough2.tec.
MOP(24)= $\quad 0, \quad$ single continuum or ECM flow field, in which case all the results written to a file tough2.tec only.
$\operatorname{MOP}(24)=1, \quad$ for dual-permeability flow fields, in which case besides the tough2.tec which represents the matrix variables, an additional output file tough_f.tec for the fracture continuum is also written.
(b) Card ELEME.1 (A5, 10X, A3, A2, 2E10.4, 10x, 3F10.3) ELEM, MA1, MA2, VOLX, AHT, X, Y, Z

Here AHT is used as an identifier for fracture elements. AHT $>0$ is for fracture elements in the dual-permeability simulations, and AHT $=0$ or default is used for matrix or single-continuum elements.

(c) Card CONNE.1

(A3, I2, A3, I2, 4I5, 4E10.4, I5) EL1, NE1, EL2, NE2, NSEQ, NAD1, NAD2, ISOT, D1, D2, AREAX, BETAX, IFM_CON

Here parameter IFM_CON identifies if the connection is fracture-fracture, fracture-matrix, or matrix to matrix. IFM_CON=0 or default is used for single-continuum or ECM block connection, and is for matrix-matrix connection in a dual-permeability grid. IFM_CON=1 is for fracture-fracture connection and IFM_CON=2 for fracture-matrix connection of a dual-permeability grid, respectively.

\subsection{Data Input for spatially varying rock properties}

The modifications required in EOS3, EOS9 and T2R3D modules to read in the spatially varying parameters corresponding to each element of the flow field is as follows:

Keyword SVPAR in the input file which can be placed anywhere after the keyword START but before ENDCY. The input file svparam.dat is needed, where the values of porosity, rock density and specific heat are given for each element with format (10X,3E10.4). 


\subsection{Brooks-Corey Relative Permeability function}

The modified form of the relative permeability to the liquid and gas phase is input through record "ROCKS" in the TOUGH2 code, and the related modifications in input data are read in card ROCKS.1.2

Card ROCKS.1.2 (15,5X,7E10.4) IRP, RP(i), $i=1,7$

IRP $=12$ for the modified form of relative permeability to gas

$R P(1)=S_{k} \quad$ residual liquid saturation van Genuchten parameter (Eq. 10)

$R P(2)=S_{g r} \quad$ residual gas saturation (Eq. 10)

$R P(3)=m^{g} \quad$ van Genuchten soil characteristic parameter (Eq. 11)

$R P(4)>0.0$ for $k_{\text {rs }}=1-k_{\text {ti }}$ (Eq. 8)

$<=0.0$ for Brooks-Corey function (Eq. 9)

\section{Summary and Conclusions}

The modifications and additions to the selected TOUGH2 modules are verified, including the ECM/EOS3, EOS9, EOS1G and T2R3D modules. Verification of this phase of the Software Life Cycle, relating to user documentation and code demonstration cases, was completed by providing with this package the sample problems described in this report. These problems also demonstrate how the user sets up certain types of problems and explore various aspects and applications of the code. Certain enhancements to the code to allow for postprocessing of the output for plotting of fluxes and velocities, and addition of new relative permeability functions have also been documented.

\section{ACKNOWLWDGWMENTS}

The authors are greatful to Don Mangold, Mark Bandurraga and H. H. Liu for their thoughtful reviews which improved the manuscript greatly. This work was supported by the Director, Office of Civilian Radioactive Waste Management, U. S. Department of Energy, through Memorandum Purchase Order EA9013MC5X between TRW Environmental Safety Systems Inc. and the Ernest Orlando Lawrence National Laboratory. The support is provided to Berkeley Lab through the U. S. Department of Energy Contract No. DE-AC03-76SF00098. 


\section{REFERENCES}

Altman, S.J.; Arnold, B.W.; Barnard, R.W.; Barr, G.E.; Ho, C.K.; McKenna, S.A.; and Eaton, R.R. 1996. Flow Calculations for Yucca Mountain Groundwater Travel Time (GWTT-95). SAND96-0819. Albuquerque, New Mexico: Sandia National Laboratory. MOL.19961106.0109, SNSAND96081900.000 (Non-Q).

Bandurraga, T.M. and Bodvarsson, G.S. 1997. Calibrating Matrix and Fracture Properties Using Inverse Modeling, Chapter 6 of Development and Calibration of the ThreeDimensional Site-Scale Unsaturated-Zone Model of Yucca Mountain, Nevada, edited by G.S. Bodvarsson, T.M. Bandurraga, and Y.S. Wu. Yucca Mountain Site Characterization Project Milestone SP24UFM4. Report LBNL-40376. Berkeley, California: Lawrence Berkeley National Laboratory. LB970601233129.001 (Q).

Bodvarsson, G.S.; Bandurraga, T.M.; Haukwa, C.; Sonnenthal, E.L.; and Wu, Y.S. 1997a. The Site Scale Unsaturated Zone Model of Yucca Mountain, for the Viability Assessment. Yucca Mountain Project Milestone SP24UFM4; Report LBNL-40376. Berkeley, California: Lawrence Berkeley National Laboratory. DTN: LB970601233129.001.

Brooks, R.H. and Corey, A.T. 1964. Hydraulic Properties of Porous Media. Hydrol. Pap., 3, 1-27. Fort Collins, Colorado: Colorado State University.

Edwards, A.L. 1972. TRUMP: A Computer Program for Transient and Steady-State Temperature Distributions in Multidimensional Systems. National Technical Information Service, National Bureau of Standards, Springfield, Virginia. NNA.19910307.0131.

Glass, R.J.; Nicholl, M.J.; and Tidwell, V.C. 1996. Challenging and Improving Conceptual Models for Isothermal Flow in Unsaturated, Fractured Rock through Exploration of Small-Scale Processes. SAND95-1824. Albuquerque, New Mexico: Sandia National Laboratories. MOL.19960620.0014.

Hinds, J.; Bandurraga, T.M.; Feighner, M.A.; and Wu, Y.S. 1997. Geology of the Unsaturated Zone and the UZ Model. Chapter 3 of The Site-Scale Unsaturated Zone Model of Yucca Mountain, Nevada, for the Viability Assessment, edited by G.S. Bodvarsson, T.M. Bandurraga, and Y.S. Wu. LBNL-40376. Berkeley, California: Lawrence Berkeley National Laboratory. LB970601233129.001

Ho, C.K. 1997. Models of Fracture-Matrix Interactions during Multiphase Heat and Mass Flow in Unsaturated Fractured Porous Media. The Sixth Symposium on Multiphase Transport in Porous Media. 1997 ASME International Mechanical Engineering Congress and Exposition, November 16-24, Dallas, Texas.

LeCain, G.D. 1997. Air-Injection Testing in Vertical Boreholes in Welded and Nonwelded Tuff, Yucca Mountain, Nevada. U.S. Geol. Surv. Water Resour. Invest. Rep. 96-4262. Denver, Colorado: U.S. Geological Survey. GS960908312232.012 (Non-Q), GS960908312232.013 (Q). 
Luckner, L.; van Genuchten, M.T.; and Nielsen, D. 1989. A Consistent Set of Parametric Models for the Two-Phase Flow of Immiscible Fluids in the Subsurface. Water Resour. Res., 25(10), 2187-2193.

Narasimhan,T.N. and Witherspoon, P.A. 1976. An Integrated Finite Difference Method for Analyzing Fluid Flow in Porous Media. Water Resour. Res., 12(1), 57-64. NNA.19890522.0253.

Pruess, K. 1983. Development of the General Purpose Simulator MULKOM. Annual Report for Earth Sciences Division - 1982, Report LBL-15500. Berkeley, California: Lawrence Berkeley National Laboratory. NNA.19910307.0133.

Pruess, K. 1987. TOUGH User's Guide. Nuclear Regulatory Commission, Report NUREG/CR-4645; Report LBL-20700. Berkeley, California: Lawrence Berkeley National Laboratory. NNA.19890315.0010.

Pruess, K. 1988. SHAFT, MULKOM, TOUGH: A Set of Numerical Simulators for Multiphase Fluid and Heat Flow. Geotermia, Rev. Mex. Geoenergia, 185-202; also Report LBL-24430, UC-251. Berkeley, California: Lawrence Berkeley National Laboratory. NNA.19910620.0128.

Pruess K. 1991. TOUGH2-A General Purpose Numerical Simulator for Multiphase Fluid and Heat Flow. Report LBL-29400. Berkeley, California: Lawrence Berkeley National Laboratory. NNA.1940202.0088.

Pruess, K.; Simmons, A.; Wu, Y.S.; and Moridis, G.J. 1996. TOUGH2 Software Qualification Report. Report LBL-38383, UC-814 Berkeley, California: Lawrence Berkeley National Laboratory. MOL19960610.0010-0020.

Thoma, S.G., Gallegos, D.P.; and Smith, D.M. 1992. Impact of Fracture Coatings on Fracture-Matrix Flow Interactions in Unsaturated, Porous Media. Water Resour. Res., 28 (5), 1357-1367. NNA.19920505.0060.

Tsang, Y. W and K. Pruess 1990. Further Modeling Studies of Gas Movement and Moisture Migration at Yucca Mountain, Nevada, Report LBL-29127 Berkeley, California: Lawrence Berkeley National Laboratory. NNA.199110405.0037.

van Genuchten. M. 1980. A Closed-Form Equation for Predicting the Hydraulic Conductivity of Unsaturated Soils, Soil. Sci. Soc. Amer. J., 44 (5), 892-898. HQS.19880517.1858.

Wu, Y.S.; Ahlers, C.F.; Fraser, P.; Simmons, A.; and Pruess, K. 1996d. Software Qualification of Selected TOUGH2 Modules. Report LBNL-39490, UC-800 Berkeley, California: Lawrence Berkeley National Laboratory. MOL.19970219.0100-0105. 


\section{Appendix A. List of input and output files}

All the 12 sample problems discussed in the text have been put on a diskette for ease of reference. The following table provides a list of the files that are available on the diskette, and it includes both the input and the output file for each of the sample problems.

\begin{tabular}{|c|c|c|c|c|}
\hline Problem description & $\begin{array}{l}\text { Revised } \\
\text { version } \\
\text { Input file }\end{array}$ & $\begin{array}{l}\text { Revised } \\
\text { version } \\
\text { Output file }\end{array}$ & $\begin{array}{l}\text { Previously } \\
\text { qualified } \\
\text { version } \\
\text { Input file } \\
\end{array}$ & $\begin{array}{l}\text { Previously } \\
\text { qualified } \\
\text { version } \\
\text { Output file } \\
\end{array}$ \\
\hline $\begin{array}{l}\text { EOS3/ECM } \\
\text { EOS3/ECM } \\
\text { spatially varving data }\end{array}$ & $\begin{array}{l}\text { probla.dat } \\
\text { prob2a.dat }\end{array}$ & $\begin{array}{l}\text { probla.out } \\
\text { prob2a.out }\end{array}$ & $\begin{array}{l}\text { prob1b.dat } \\
\text { prob2b.dat }\end{array}$ & $\begin{array}{l}\text { prob1b.out } \\
\text { prob2b.out }\end{array}$ \\
\hline $\begin{array}{l}\text { EOS9- dual } \mathrm{k} \\
\text { fracture-matrix interaction } \\
\text { ISOT }=-1\end{array}$ & prob3a.dat & prob3a.out & prob3b.dat & prob3b.out \\
\hline $\begin{array}{l}\text { EOS9-dual k } \\
\text { fracture-matrix interaction }\end{array}$ & prob4a.dat & prob4a.out & prob4b.dat & prob4b.out \\
\hline $\begin{array}{l}\text { EOS9- dual k } \\
\text { fracture-matrix interaction } \\
\text { ISOT }=-4\end{array}$ & prob5a.dat & prob5a.out & prob5b.dat & prob5b.out \\
\hline $\begin{array}{l}\text { EOS9- dual } \mathbf{k} \\
\text { fracture-matrix interaction } \\
\text { ISOT }=-7\end{array}$ & prob6a.dat & prob6a.out & prob6b.dat & prob6b.out \\
\hline $\begin{array}{l}\text { EOS9- dual } \mathrm{k} \\
\text { fracture-matrix interaction } \\
\text { ISOT }=-8\end{array}$ & prob7a.dat & prob7a.out & prob7b.dat & prob7b.out \\
\hline $\begin{array}{l}\text { EOS9- dual } \mathbf{k} \\
\text { fracture-matrix interaction } \\
\text { ISOT }=-9\end{array}$ & prob8a.dat & prob8a.out & prob8b.dat & prob8b.out \\
\hline $\begin{array}{l}\text { EOS9- dual } k \\
\text { vitric/zeolitic interface } \\
\text { modified weighting } \\
\text { ISOT }=-2\end{array}$ & prob9a.dat & prob9a.out & prob9b.dat & prob9b.out \\
\hline $\begin{array}{l}\text { Post-processing for } \\
\text { velocity and fluxes }\end{array}$ & prob10.dat & prob10.out & & \\
\hline $\begin{array}{l}\text { T2R3D } \\
\text { transport in dual } k\end{array}$ & prob11a.dat & prob11a.out & prob11b.dat & probl1b.out \\
\hline & prob12a.dat & prob12a.out & prob12b.dat & prob12b.out \\
\hline
\end{tabular}




\section{Appendix B. TOUGH2 code source files}

The revised and updated versions of the software constituting version 1.3 of TOUGH2 have been put together on a diskette. All the souce code for TOUGH2 are available on 3.5" high-density diskette, written in PC-DOS ASCII format. The distribution includes the following 19 files :

The following is a list of the files that are available:

1. $\operatorname{tegn} 2 . \mathrm{f}$

2. meshmn.f

3. eos3ecm.f

4. $\cos 9 \mathrm{ecm} . \mathrm{f}$

5. eos321.f

6. eos1g.f

7. $t 2 \mathrm{fecm} . \mathrm{f}$

8. $t 2 f 212 . f$

9. t2fecmlg.f

10. inter.f

11. relpecm.f

12. relplg.f

13. pcapecm.f

14. sndibm.f

15. corder.f

16. diffd.f

17. $\operatorname{gradx} . f$

18. tough2.prm

19. matb.com contains the main program of TOUGH2, with PARAMETER

statements and initialization of disk files

module with internal mesh generation facilities

equation of state for water/air with ECM option

equation of sate for water/air with air treated as a passive phase and

ECM option

equation of state for water, air and radionuclide

equation of state for water/air with water treated as a passive phase

modified to include ECM option from 2f.f of TOUGH2 Version

1.11 ; it reads input data, initializes arrays and parameters, sets up

Newton-Raphson iteration, and performs time stepping; it also contains the water property routines (steam table equations) and the relative permeability and capillary pressure functions which are used in the equation-of-state modules

similar to 2 fecm.f used in the T2R3D module

similar to 2 fecm.f used in the eos $1 \mathrm{~g}$ module

an iterative sparse matrix solver for block matrices (Copyrighted)

evaluating relative permeability with ECM option

evaluating relative permeability for EOS1G

evaluating capillary pressure with ECM option

computing time subroutine

subroutine to sort indexes of all connections for each element, used in T2R3D

subroutine to calculate hydraulic dispersion and molecular diffusion tensor, used in T2R3D

subroutine to calculate concentration gradients, used in T2R3D

Parameter 'INCLUDE' file to set up dimensions of arrays used in the TOUGH 2 code

Parameter file for the solver

Source codes for the different TOUGH 2 modules

The TOUGH2 EOS3/ECM module:

t2cgn2.f

t2fecm.f

meshmn.f

eos3ecm.f

relpecmn.f

inter.f

pcapecm.f

pcapgen.f

sndibm.f

tough2.prm

matb.com 
The TOUGH2 EOS1G module:

t2cgn2.f

t2fecm1g.f

meshmn.f

eosig.f

relp1g.f

inter.f

pcapecm.f

pcapgen.f

sndibm.f

tough2.prm

matb.com

The TOUGH2 EOS9 module:

t2cgn2.f

t2f_9.f

meshmn.f eos9_up.f

relpecmn.f

inter.f

pcapecm.f

sndibm.f

tough2.prm

matb.com

The TOUGH2 T2R3D module

t2cgn2.f

t2f212.f

meshmn.f

eos321.f

relpecmn.f

inter.f

pcapecm.f

pcapgen.f

sndibm.f

gradx.f

diffd.f

corder.f

tough2.prm

matb.com 